\title{
WestVirginiaUniversity
}

THE RESEARCH REPOSITORY @ WVU

Graduate Theses, Dissertations, and Problem Reports

2008

\section{Thermal analysis of tilted roofs composed of two separated surfaces}

Orlando J. Ugarte-Almeyda

West Virginia University

Follow this and additional works at: https://researchrepository.wvu.edu/etd

\section{Recommended Citation}

Ugarte-Almeyda, Orlando J., "Thermal analysis of tilted roofs composed of two separated surfaces" (2008). Graduate Theses, Dissertations, and Problem Reports. 2086.

https://researchrepository.wvu.edu/etd/2086

This Thesis is protected by copyright and/or related rights. It has been brought to you by the The Research Repository @ WVU with permission from the rights-holder(s). You are free to use this Thesis in any way that is permitted by the copyright and related rights legislation that applies to your use. For other uses you must obtain permission from the rights-holder(s) directly, unless additional rights are indicated by a Creative Commons license in the record and/ or on the work itself. This Thesis has been accepted for inclusion in WVU Graduate Theses, Dissertations, and Problem Reports collection by an authorized administrator of The Research Repository @ WVU. For more information, please contact researchrepository@mail.wvu.edu. 


\title{
THERMAL ANALYSIS OF TILTED ROOFS COMPOSED OF TWO SEPARATED SURFACES
}

\author{
Orlando J. Ugarte-Almeyda
}

Thesis submitted to the

College of Engineering and Mineral Resources

at West Virginia University in partial fulfillment of the requirements

for the degree of

\author{
Master of Science \\ in \\ Mechanical Engineering
}

James E. Smith, Ph.D., Chair

Ever J. Barbero, Ph.D.

Scott W. Wayne, Ph.D.

Emily D. Pertl, MS.

Department of Mechanical and Aerospace Engineering

Morgantown, West Virginia
2008

Keywords: natural convection, ventilation, double roof. 


\section{ABSTRACT \\ THERMAL ANALYSIS OF TILTED ROOFS COMPOSED OF TWO SEPARATED SURFACES}

\section{Orlando J. Ugarte-Almeyda}

Due to the rising power costs and lack of nonrenewable energy sources, the cooling of houses is becoming more expensive. Looking for alternative methods applicable to this process is becoming not only an option, but also a necessity. Changes in the roof structure of buildings can be applied in order to achieve a more favorable thermal transmission behavior. The utilization of a tilted roof, composed of two separated surfaces, generates natural convection currents in the channel between them. These currents, after driving off part of the transferred heat, decrease the temperature of the lower surfaces and consequently, the heat flux through the ceiling into the living areas.

The natural convection phenomenon is treated by numerical means, and the influence of the dimensions of the proposed design on the ventilation rates is analyzed in order to determine the most efficient geometry. The comparison of thermal performances between the proposed roof and a typical unventilated design is also established in order to realize the quantitative advantage of the proposed model.

Results show that the separation between surfaces strongly influences the process within certain values; i.e. a reduction in the heat flux through the ceiling achieved by the system of $32.9 \%$ can be raised to $45.4 \%$ by increasing the width of the channel from $0.05 \mathrm{~m}$ to $0.15 \mathrm{~m}$, and keeping the other dimensions constant. Moreover, higher tilt angles also improve natural ventilation rates. For example, a 32.8\% reduction obtained by the system at a 30 degree tilt angle grows up to $41.6 \%$ by raising the tilt angle to 65 degrees. A vertical extension or exhaust channel on the top increases the reduction of heat flux too, but with less intensity. In this sense, the heat flux reduction achieved by the system, when the vertical exhaust length is $12.5 \%$ of the length of the roof , increases from $32.9 \%$ to $45.5 \%$ when a considerably bigger vertical extension is used, $60 \%$ of the roof length. 


\section{DEDICATION}

To HIM, my strength and my shield 


\section{ACKNOWLEDGEMENT}

Many people deserve much more acknowledgement that my best effort showing their names here can provide, not only because their help and support, but because the advices and good examples from which I have learned the last two years and before.

I would like to thank to the Department of Mechanical and Aerospace Engineering, beginning with Dr. Barbero, the person who introduced West Virginia University into my goals, and Dr. Prucz for all his support and patience. Likewise, my recognition is to my teachers, for sharing such nice and challenging lessons, and to the people in every office. All of them are the most competent team that I met so far.

I want to express my sincere gratitude to my advisor, Dr. James Smith and the Center for Industrial Research Applications (CIRA) for the opportunity given to be part of this outstanding group. Their guidance and experience constituted the key factors in this research experience. I really appreciate all their aid.

My special thanks to my family, which is my diary motivation. To my mentor in Peru, Dr. Guillermo Quevedo, I really appreciate what you taught me dear friend. To my friends, in especial Hermann Alcazar, Eduardo Perez, Omar Meza and family, Fito Pino, and every guy that made my life easier. To Maite, my partner, there are not enough miles in the world to keep us separated. All my deepest thankfulness is for all of you.

Finally, the most important recognizing is for the person that makes all these possible, to whom I want to be the nearest, above my weaknesses and doubts, your name is the fire that nothing could extinct in my heart, thanks so much Jesus. 


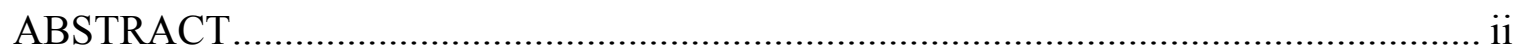

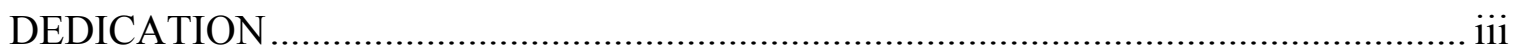

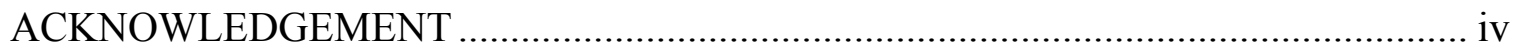

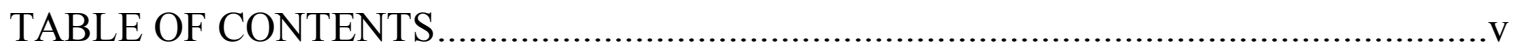

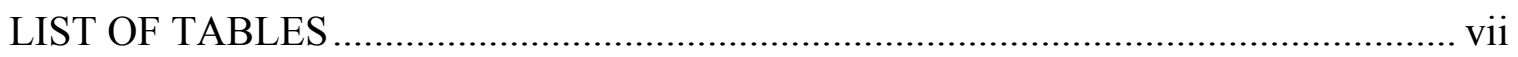

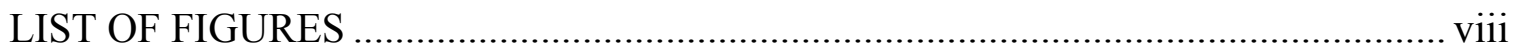

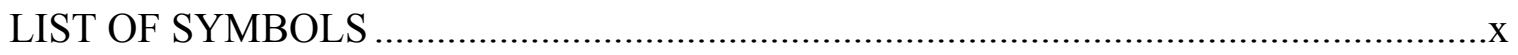

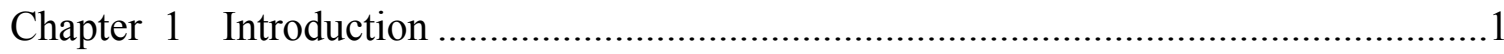

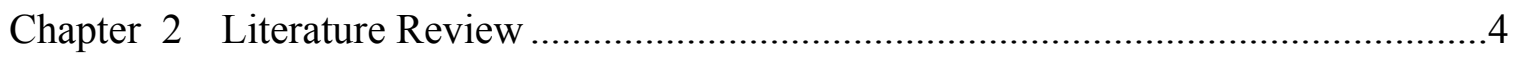

Chapter 3 Research Methodology .....................................................................11

3.1 Principles applied in heating and cooling of building: an overview. ...................12

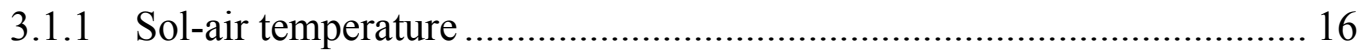

3.1.2 Heat transfer mechanism through walls ............................................... 18

3.1.3 Heat transfer through attics: .................................................................. 19

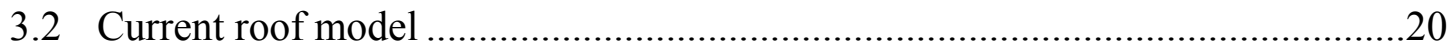

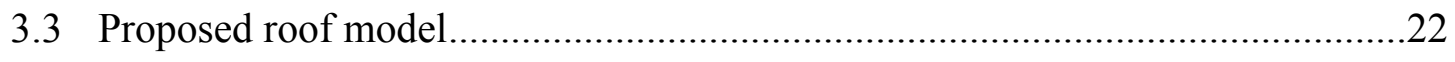

3.3.1 Proposed roof description ............................................................... 22

3.3.2 Governing equations of the natural ventilation process .......................... 23

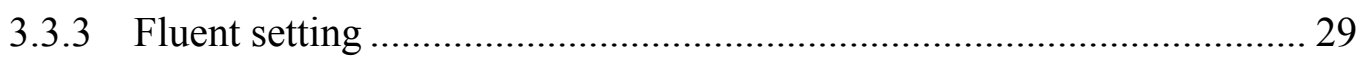

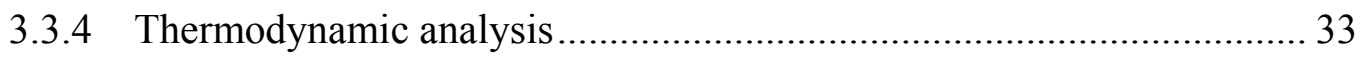

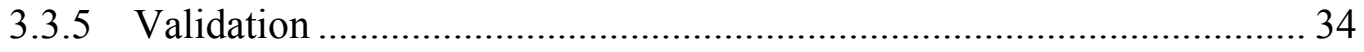




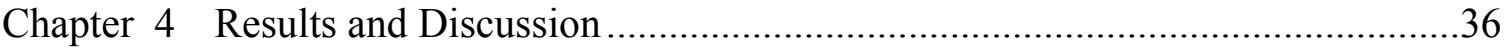

4.1 Temperature distribution in the roof-ceiling system ..........................................36

4.2 Velocity profiles in the channel exit....................................................................

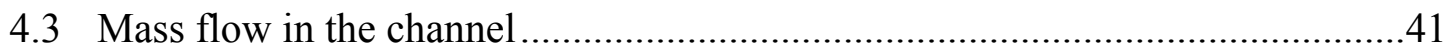

4.4 Temperature of the ceiling............................................................................42

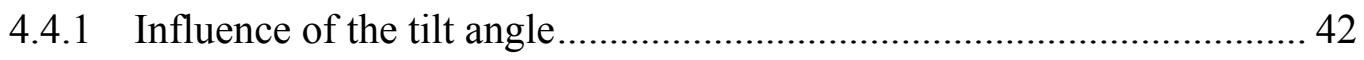

4.4.2 Influence of the width of the channel ..................................................... 43

4.4.3 Influence of the vertical extensions ........................................................ 45

4.5 Heat flux through the ceiling ...........................................................................4

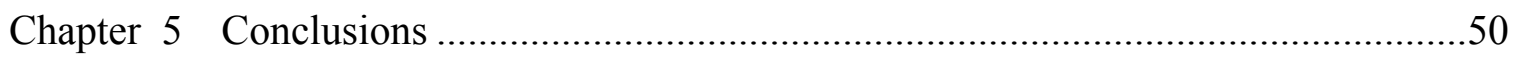

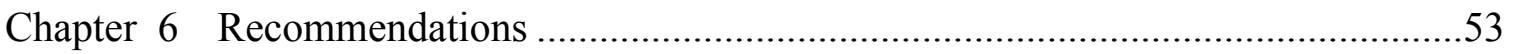

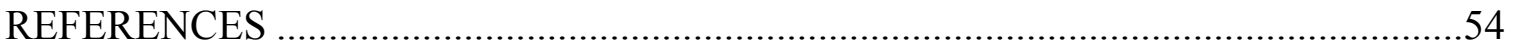




\section{LIST OF TABLES}

Table 1. Roof components and R-Value ........................................................21

Table 2. Ceiling components and R-Value .........................................................21

Table 3. Dimensions used for the different cases ................................................... 30 


\section{LIST OF FIGURES}

Figure 1. Energy consumption in the last three years in the United States.................2

Figure 2. Effect of the sun-air temperature replacing the convection and

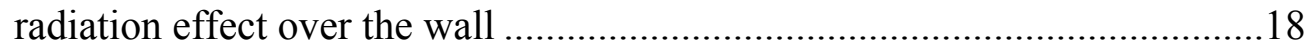

Figure 3. Thermal resistance networks through a plane wall...................................19

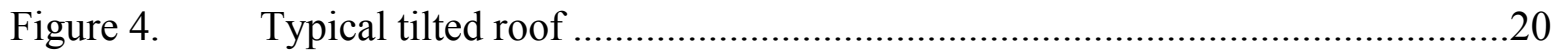

Figure 5. Proposed roof model ..........................................................................22

Figure $6 . \quad$ Velocity profile in the channel...........................................................25

Figure 7. Variables involved in the proposed roof construction ..............................30

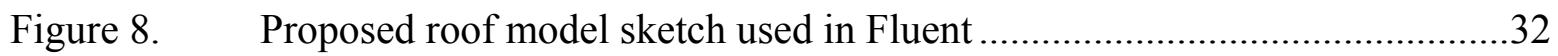

Figure 9. Heat load over the roof-attic-ceiling system .......................................33

Figure 10. Comparison of data obtained from experimental and numerical

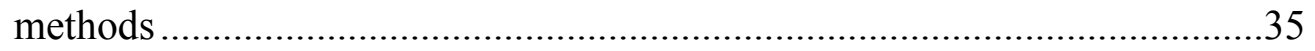

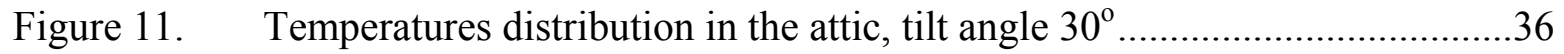

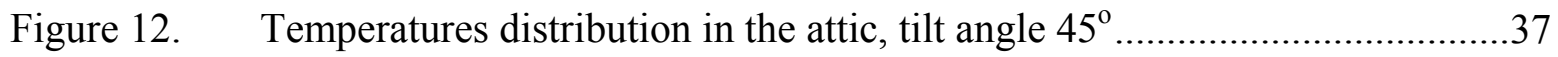

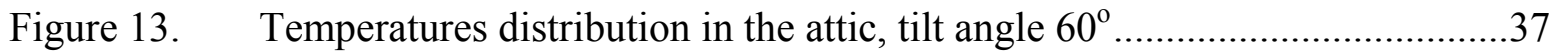

Figure 14. Velocity vectors in the inlet (left) and outlet (right) .................................38 
Figure 15. Velocity profiles in the outlet

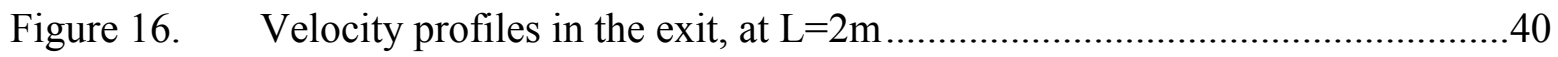

Figure 17. Velocity profile in the exit under 45 tilt angles .........................................40

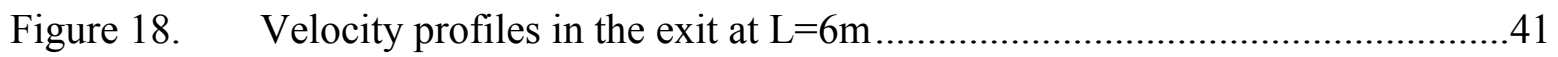

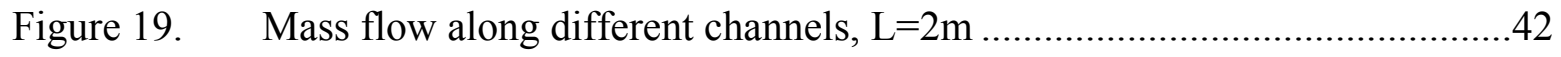

Figure 20. Temperature comparison in the ceiling at different tilt angles ....................43

Figure 21. Temperature distribution in the ceiling, different channel widths $[\mathrm{m}]$.........44

Figure 22. Mean temperature at the ceiling at different channel widths .......................45

Figure 23. Ceiling temperature at different vertical extensions ..................................46

Figure 24. Variation of the mean temperatures of the ceiling, at different vertical

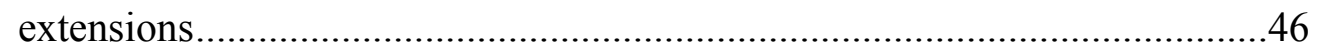

Figure 25. Comparison of ceiling temperatures at different vertical extension and

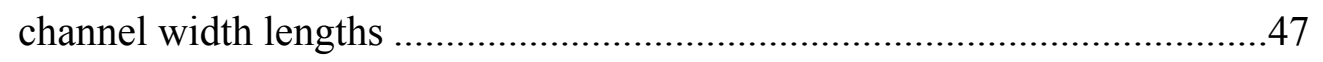

Figure 26. Heat flux through the ceiling at different dimensions ..............................48

Figure 27. Comparison of ceiling heat fluxes at different vertical extension and channel width lengths 


\section{LIST OF SYMBOLS}

\begin{tabular}{|c|c|}
\hline$A$ & Area \\
\hline C & Specific heat, $\mathrm{kJ} / \mathrm{kg} \cdot \mathrm{K}$ \\
\hline$C_{P}$ & Constant pressure specific heat, $\mathrm{kJ} / \mathrm{kg} \cdot \mathrm{K}$ \\
\hline$C_{V}$ & Constant volume specific heat, $\mathrm{kJ} / \mathrm{kg} \cdot \mathrm{K}$ \\
\hline$E$ & Total energy, $k J$ \\
\hline$F$ & Force, $N$ \\
\hline$g$ & Gravitational acceleration, $\mathrm{m} / \mathrm{s}^{2}$ \\
\hline$G r$ & Grashof number \\
\hline$h$ & Enthalpy, $u+P v, k J / k g$ \\
\hline$h$ & Convection heat transfer coefficient, $\mathrm{W} / \mathrm{m}^{2} \cdot{ }^{\circ} \mathrm{C}$ \\
\hline$h_{f g}$ & Latent heat of vaporization, $\mathrm{kJ} / \mathrm{kg}$ \\
\hline$k$ & Thermal conductivity \\
\hline$L$ & Length \\
\hline$m$ & Mass, $k g$ \\
\hline$m$ & Mass flow rate, $\mathrm{kg} / \mathrm{s}$ \\
\hline $\mathrm{Nu}$ & Nusselt number \\
\hline & Perimeter, $m$ \\
\hline
\end{tabular}




\begin{tabular}{ll}
$P$ & Pressure, $k P a$ \\
Pr & Prandtl number \\
$Q$ & Total amount of heat transfer, $k J$ \\
$\dot{q}$ & Heat flux, $W / \mathrm{m}^{2}$ \\
$\dot{Q}$ & Heat transfer rate, $k W$ \\
$R$ & Thermal resistance, ${ }^{0} \mathrm{C} / \mathrm{W}$ \\
$R a$ & Rayleigh number \\
$R-$ value & R-value of insulation \\
Re & Reynolds number \\
$t$ & Time, $s$ \\
$T$ & Temperature, ${ }^{\circ} \mathrm{C}$ or $\mathrm{K}$ \\
$U$ & Overall heat transfer coefficient, $W / \mathrm{m}^{2} .{ }^{\circ} \mathrm{C}$ \\
$\dot{V}$ & Total volume, $\mathrm{m}^{3}$ \\
$\dot{W}$ & Volume flow rate, $\mathrm{m}^{3} / \mathrm{s}$ \\
$\dot{V}$ & Power, $k W$ \\
\hline
\end{tabular}

\section{Greek Letters}

$\alpha$

$\alpha$

$\beta$
Absorptivity; thermal diffusivity, $\mathrm{m}^{2} / \mathrm{s}$

Tilt angle

Volume expansion coefficient, $1 / K$ 


$\begin{array}{ll}\varepsilon & \text { Emissivity; heat exchanger or fin effectiveness } \\ \lambda & \text { Thermal conductivity, } \mathrm{J} / \mathrm{msK} \\ \mu & \text { Dynamic viscosity, } \mathrm{kg} / \mathrm{m} \cdot \mathrm{s} \\ v & \text { Kinematic viscosity } \mathrm{m}^{2} / \mathrm{s} \\ \rho & \text { Density, } \mathrm{Kg} / \mathrm{m}^{3} \\ \sigma & \text { Stefan-Boltzman constant } \\ \theta & \text { Dimensionless temperature }\end{array}$

\section{Subscripts}

$\begin{array}{ll}\text { atm } & \text { Atmospheric } \\ i & \text { Inlet, initial or indoor conditions } \\ \text { o } & \text { Outdoor conditions } \\ \text { rad } & \text { Radiation } \\ \text { surr } & \text { Surrounding surfaces } \\ \text { sys } & \text { System } \\ \infty & \text { Ambient conditions }\end{array}$

\section{Superscripts}

(over dot) Quantity per unit time 


\section{Chapter $1 \quad$ Introduction}

Fossil fuels and other nonrenewable and renewable sources of energy are used worldwide for thermal comfort. Even with the rising costs that they have been experiencing in recent years, environmental conditioning is desired and in some places, absolutely needed. In addition, their applications are pulled by the growing construction business. Historically, protection against harsh environmental conditions has forced human beings to search for places and mechanisms that can provide them with some thermal comfort. However, while heating was developed, even in the old days by open fire or primitive chimneys, cooling systems took extra time to appear, since no quick way to produce 'coolness' was available. With time, several devices were developed providing additional thermal comfort conditions. Actually, not only a comfortable heating and cooling level is regulated by current air-conditioning systems, but humidity, cleanness and deodorization levels are controlled as well.

Conditions which let the body feel comfortable have been investigated extensively, being found to be at temperatures from $73^{\circ} \mathrm{F}$ to $80^{\circ} \mathrm{F}$ (considering clothed people resting or doing light work), relative humidity in the range of 30 to 70 percent (being 50 percent the most desirable level) and air velocity below $9 \mathrm{~m} / \mathrm{min}$ in winter and $15 \mathrm{~m} / \mathrm{min}$ in summer to minimize discomfort caused by a draft [1]. These rates are considered the indoor conditions for thermal comfort. The weather, which in some locations varies greatly from month to month and even from hour to hour, is the outdoor 
condition which, in addition to the indoor condition, constitutes the parameters used for the air-conditioning system design.

Temperatures in buildings are affected by different sources: heat gained by lights, appliances and people; heat transferred through the walls and roofs; and heat loss to the basement. The heat gained and lost strongly affect the energy spending in dwellings, as seen in Figure 1 [2], where the higher consumptions are at the hottest months(July and August) and the coolest months (December and January).

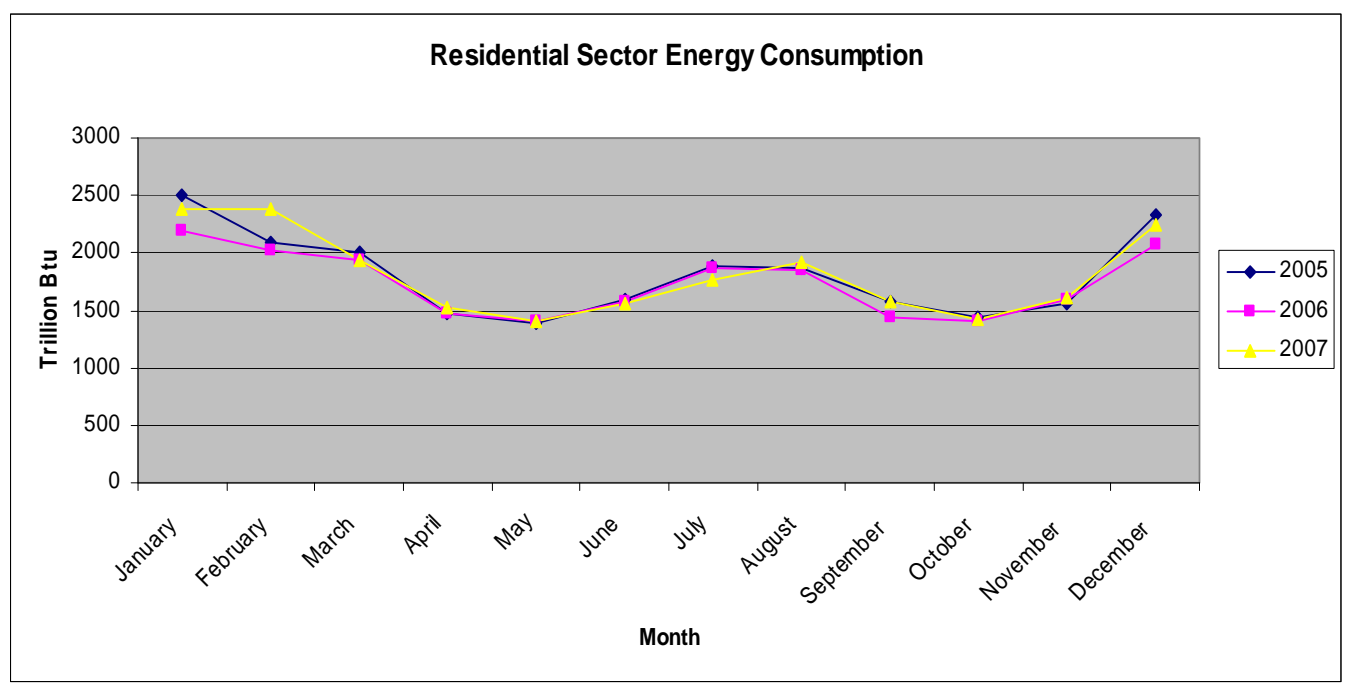

Figure 1. Energy consumption in the last three years in the United States

Natural ventilation is the process by which air is supplied and removed from enclosures by natural means. It has been applied for centuries in the construction of buildings, often constituting the motivation of many geometries and styles. Similarly, the phenomenon has been enhanced in dwellings by applying changes at different parts of the structure, such as roofs, walls, floors or basements, in one-story and even in multi-story buildings. 
The aim of this study is to analyze the geometric conditions under which an innovative naturally ventilated roof will minimize the heat load into the building in summer. The roof is composed of two parallel surfaces, separated from each other forming a channel in line with the angle of the roof. During warm temperature conditions, the air in the channel is heated, producing natural convection currents. This flow drives off part of the heat transferred through the upper surface. After setting the appropriate governing equations, numerical methods are used to find the thermal response of the proposed design. A comparison of the results with those obtained by current roofs, similarly tilted, illustrates how valuable this new design could be.

The objective of this research is to use natural convection for the reduction of energy consumption of air conditioning systems in summer. The proposed roof design is applicable in most houses, where tilted roofs are typically used to deal with rain and snow. Due to the transferred heat, the temperature inside the dwelling should be expected to be greater than the temperature outside; then, the necessity of extra ventilation will depend on the weather conditions. Likewise, the benefits analyzed are only related to summer conditions; the behavior of this roof in winter has not been evaluated.

The treatment of the problem is shown in four sections; chapter two shows familiarization with current information about induced ventilation and its applications through the literature review. In Chapter three, the research methodology used along the problem solution is established and described. Chapter four shows the results and discussion of the solution data, and finally Chapters five and six present the conclusions and recommendations for future work, respectively. 


\section{Chapter 2 Literature Review}

This chapter presents a brief review of studies and applications related to the topic of this research. The discussion begins with the phenomenological statement of the problem, followed by the analysis of one-cavity enclosures and multiple-partition enclosures of different shapes. The relation with dwelling designs is initially mentioned at the two floor enclosure case, where the radiation effect of a heater is observed. Combined effects of natural convection and radiation over the external surfaces of buildings are shown through the analysis of solar roof collectors, attics and double skin roofs, being the latter the closest model to that proposed in this work. In the last part, a natural ventilation system proposed for a multi-story building is studied, concluding with some examples of applications and patents introduced in fields other than buildings, such as electronics, automotive, etc.

Natural ventilation is based on buoyancy forces [3] and consequently in buoyancy flows. These flows have challenging physical and mathematical problems with the coupling of elements such as the transport phenomenon, boundary-layers, core flows, interaction between the flow and driven force and the occurrence of flow sub-regions.

The behavior of air in heated, ventilated enclosures was treated by Dubovsky et al. [4]. In this study, two general cases were analyzed: an open and a closed box, both heated by a horizontal downward-facing hot plate. By using experimental and numerical methods at transient and steady states, it was found that the natural convection at the open 
case reduces the temperature inside the box. Three different positions for the entrance to the open box were considered: top, middle and bottom, where the most effective was the bottom. Nishimura et al. [5] conducted a laminar natural convection study in rectangular enclosures with multiple vertical partitions, showing that, in the boundary layer regime, the partition temperature increases almost linearly in the vertical direction. Moreover, the Nusselt number was inversely proportional to the number of partitions.

Since most attics represent triangular enclosures, natural convection is important in this geometry. Poulikakos and Bejan [6] analyzed the fluid dynamics of a triangular enclosure composed of a cold upper wall and a warm horizontal bottom wall. Transient (beginning with the sudden cooling of the upper wall) and steady-state circulation flow patterns and temperature fields were presented, the latter by an asymptotic analysis. Flack et al. [7] studied the thermal response of an isosceles triangular enclosure composed by two isothermal sides and an insulated bottom; where experimental data was obtained. Later, Flack et al. [8] theoretically predicted the velocities of the flow field in a triangular enclosure, previously studied, in order to elucidate heat transfer correlations.

Combined surface radiation and free convection was investigated by Balaji and Venkateshan [9], considering an enclosure occupied by air. Their study showed that when radiation is added to the system, an offset to the reduction on convective heat transfer along the cavity occurs. Behnia et al. [10] studied numerically this combined effect in a rectangular, two-dimensional enclosure full of a nonparticipating fluid. The flow pattern and heat transfer were investigated in the cavity, the terminal temperature difference was $130^{\circ} \mathrm{C}$ and the Rayleigh number values were between $10^{4}$ and $3 \times 10^{5}$. 
The air not only can be treated as a natural ventilation medium, but can also act, under certain conditions, as a natural insulation medium. For example, referring to 'environmentally friendly houses', vertically perforated bricks were developed to reduce the need for insulating materials in walls [11]; the vertical direction reduces convection in this zone, limiting heat transfer through the wall considerably.

Induced ventilation has been applied at different building parts, considering the sun or common heaters as heat sources in rooms and over surfaces, such as walls and roofs. Ergin [12] investigated the surface thermal response of a heated two-floor enclosure. The system was composed of two floors connected via a stairway; the room had a heater in which two different input rates of $300 \mathrm{~W}$ and $600 \mathrm{~W}$ were applied. Open and closed enclosures were analyzed. The investigation concluded that the through-flow effect on the wall is mainly done by convection.

Natural ventilation mechanisms applied to the external surfaces of the building have been developed according to concepts, such as the solar chimney effect, which lets the air move between heated surfaces. Bansal et al. [13] studied inclined solar chimneys by proposing a steady state mathematical model. After evaluating different ambient temperatures and solar radiation loads, they showed that a solar collector with area of $2.25 \mathrm{~m}^{2}$, inclined $30^{\circ}$ with the horizontal, induced airflows between $140 \mathrm{~m}^{3} / \mathrm{h}$ and $330 \mathrm{~m}^{3} / \mathrm{h}$ for solar radiation values of $200 \mathrm{~W} / \mathrm{m}^{2}$ and $1000 \mathrm{~W} / \mathrm{m}^{2}$, respectively. Chen et al. [14] carried out an investigation by using an experimental solar chimney model with uniform heat flux. Different dimensions in the gap and height lengths were evaluated. In these studies, the geometry that allowed the maximum airflow was given by an inclination of $45^{\circ}, 200 \mathrm{~mm}$ of gap and $1.5 \mathrm{~m}$ chimney height. Aboulnaga and Abdrabboh [15] analyzed a 
combined wall-roof solar chimney to improve night-time ventilation in buildings, reporting that this system can induce an airflow rate of $0.81 \mathrm{~m}^{3} / \mathrm{s}$ at an average solar radiation of $850 \mathrm{~W} / \mathrm{m}^{2}$; in addition, the maximum airflow was $1.1 \mathrm{~m} / \mathrm{s}$, obtained at $25^{\circ}$ of inclination and $0.25 \mathrm{~m}$ of separation between chimney plates.

Mathur et al. [16] investigated an induced solar ventilation system and the variations produced by the inclination of the solar absorber on the airflow rate. The optimum absorber inclination varied from $40^{\circ}$ to $60^{\circ}$ for a maximum rate of ventilation. Moreover, solar collector systems have been proposed worldwide, e.g. Mathews [17], Lanyon [18], Pigg [19] and Stoll et al. [20].

Among the studies that consider the roof as part of the natural ventilation system, it is necessary to mention Asan and Namli [21] [22] who computationally solved a two dimensional, laminar natural convection problem of a roof with a triangular cross-section; considering summer and winter-day boundary conditions. Tzeng et al. [23] developed a numerical simulation-aided parameter for natural simulation in a roof of a triangular enclosure. Messick [24] patented a system for attic ventilation using spaced apart purlins and a ceiling sheathing, fixed to the top edge, providing plenum areas between the parts. In this study, vents and a fan draw air through the plenum areas, discharging it exteriorly.

Thong et al. [25] introduced the analysis of a solar roof collector by modeling a heated wall over a two dimensional air gap, considering tilt angles between $15^{\circ}$ and $55^{\circ}$ and different air gap heights. The most practical incorporation of solar roof collector into a single story structure (in comparison for example with a Trombe Wall), plus the fact that this configuration is expected to collect more solar radiation without changing the 
overall dwelling architecture, make this mechanism attractive in adaptability and efficiency.

Some combinations of components and techniques for supporting roofs have given excellent thermal characteristics. Miller et al. [26] observed a counter-batten construction which provides an air space between the exterior face of the roof sheathing and the underside of the roof cover. In this air pathway beneath the roof, the air, heated by solar irradiance, is moved up along it. This thermally induced airflow, termed abovesheathing ventilation, was proposed as a method to remove unwanted heat and moisture from the roof deck, improving not only the roof thermal performance, but its durability. Miller et al. [27] developed an algorithm for predicting rates of airflow and heat flow induced by free convection, prevalent in roofs elevated from the roof deck. The validation of the routine was done against thermal field data for stone-coated metal roofs equipped with above-sheathing ventilation.

Under-roof cavities where analyzed by Fracastoro et al. [28]. They proposed a model for steady-state thermal analysis of ventilated and unventilated light roofs, using air temperature distributions, surface temperatures, heat fluxes and air flow rates as output data. The algorithm had to be initialized with values near of the solution. LacenaNeildez [29] faced a one-dimensional numerical and experimental analysis of a doubleskin metal roof for warm countries. In this study, roof dimensions, slope and external wind velocity on the passive ventilation capacity was analyzed. Greater attention was put to the influence of surface emissivity, which was recognized as the major parameter for efficiency. 
Biwole et al. [30], after examining a double-skin roof ventilated by natural convection in summer time, proposed the most important parameters in the efficiency of the system. In the order of importance these were the sheet metal surface emissivity, the screen internal and external surface emissivity, the insulation thickness and the inclination angle for a channel width over $6 \mathrm{~cm}$. Discussions about the Rayleigh and Nusselt number were also presented.

Chang et al. [31] experimentally evaluated the incorporation of a radiant barrier system in a double-skin roof and the energy savings achieved. Azevedo and Sparrow [32] established relations for the Nusselt and Rayleigh numbers, evaluating two differentially heated open-ended and tilted parallel plates dealing with angles from $45^{\circ}$ to $90^{\circ}$.

Concerned with more than one-story buildings, Letan et al. [33], and Letan et al. [34] considered the passive ventilation and heating of a multi-story structure by natural convection. Numerical and experimental investigations were carried out in the system composed of a five-story building and two metallic open ducts installed at each side, being only one of them heated by the sun. Natural ventilation is achieved in the warmer duct, and then conducted along the building by the ducts and every floor through ports. This system is also heated when the ducts are closed and the air coming from the warmer duct passed through the building by the same (now closed) circuit. Clearly, in both cases; the air stream is in contact with the interior and its occupants.

In addition, devices such as electronic equipments (Ostrach [35]), car-roof (Link [36], Bird et al. [37]), mobile homes (Struben [38]), house trailers (Orter [39]), ISO containers shelters (Hartzell et al. [40]), food storages (Hansen [41]), vehicles (Wittrien [42]) or power transmission lines have been designed to facilitate natural ventilation. 
To conclude, this brief summary has shown the variety of applications that natural convection has had in different devices. In dwellings, the roof and walls are the most used surfaces because of their notable effect on the structure heat input. The proposed roof introduces the vertical extension of the channel, attempting to improve natural ventilation rates obtained so far in houses. 


\section{Chapter 3}

\section{Research Methodology}

Considering the nature of the problem, a quantitative-qualitative perspective has been employed for the solution. In order to realize what key factors were involved, numerical values were obtained (quantitative) and evaluated according to their meaning and influence in the phenomenon (qualitative). This chapter covers a summary of the theoretical support, a description of the analyzed models, and an explanation of the strategy followed in the solution.

The research took place in 2008, when perhaps one of the major concerns has been energy utilization and its impact on the environment. The analysis of the proposed roof involved the momentum and energy equations which have been treated by numerical methods and software packages. The material used was principally articles and books published in natural ventilation, heat transfer and fluid mechanics; reports on thermal behavior of current roof designs, bibliography on numerical methods and software packages such as MATLAB, Fluent and Gambit.

The research process includes the evaluation under summer conditions of two roof designs: a typical tilted roof and a similarly tilted structure composed of two parallel surfaces. Both designs have an unventilated attic space between the roof and ceiling. Natural currents of air between surfaces are expected in the second model, ventilating the lower surface, in contact with the attic, and driving off part of the heat transferred from the outer surface. The possibility to reduce this heat flux into the dwelling and the 
corresponding reduction in the air conditioning power consumption will be an indicator of the success of the proposed model.

Information based on the thermal behavior of each model is necessary in order to measure the effectiveness (or not) of the proposed model. However, while the typical roof evaluation can be done through methods available for heat transfer in buildings, the proposed roof evaluation involves, in addition, a natural convection analysis and will be

divided in the following steps. First, the description and establishing of the corresponding variables, assumptions, governing equations and boundary conditions involved in the problem. Second, the strategy to be used in Fluent is applied to similar natural convection cases, experimentally studied, in order to verify the accuracy of the method. Third, the problem is solved with the verified method, and finally in the fourth stage, the results are processed, looking for the most convenient values of the parameters analyzed.

\subsection{Principles applied in heating and cooling of building: an overview.}

The heating or cooling loads of a building correspond to the heat to be removed or supplied to the interior in order to keep it at the desirable thermal condition. The mechanisms at which heat loads are transferred to the building have multiple sources [1].

\section{a) Heat gain from people, lights and appliances}

This heat comes from the conversion of electrical and chemical energy to heat. The average heat given off by a person varies depending on the activity, i.e. about $100 \mathrm{~W}$ for a resting person and more than $500 \mathrm{~W}$ for a physically active one. The lighting energy 
consumption in office buildings is about 20 to $30 \mathrm{~W} / \mathrm{m}^{2}$ of floor space. Furthermore, heat gain by a motor inside a room can be calculated by:

$$
\dot{Q}_{\text {motor, total }}=\dot{W}_{\text {motor }} \times f_{\text {load }} \times f_{\text {usage }} / \eta_{\text {motor }},
$$

where:

$$
\begin{aligned}
& \dot{W}_{\text {motor }}: \text { Power rating of the motor } \\
& f_{\text {load }}: \text { Load factor of the motor during operation } \\
& f_{\text {usage }}: \text { Usage factor } \\
& \eta_{\text {motor }}: \text { Motor efficiency }
\end{aligned}
$$

\section{b) Heat transfer through walls and roof}

At steady conditions, the rate of heat transfer through the roof and walls can be determined from:

$$
\dot{Q}=U A\left(T_{i}-T_{o}\right)=\frac{A\left(T_{i}-T_{o}\right)}{R} .
$$

Here $U$ is the overall heat transfer coefficient (U-factor), $A$ the heat transfer area, $T_{i}$ and $T_{o}$ are the indoor and outdoor air temperatures, and $R$ the overall unit thermal resistance (R-value).

\section{c) Heat loss from basement walls and floors}

If different regions are to be evaluated, through the below-grade section of a basement wall and through the basement floor; the heat loss in these zones are computed by: 


$$
\begin{aligned}
& \dot{Q}_{\text {basement walls }}=U_{\text {wall,ave }} A_{\text {wall }}\left(T_{\text {basement }}-T_{\text {ground surface }}\right) \\
& \dot{Q}_{\text {basement floor }}=U_{\text {floor }} A_{\text {floor }}\left(T_{\text {basement }}-T_{\text {ground surface }}\right)
\end{aligned}
$$

In this case:

$U_{\text {wall,ave }}:$ Average overall heat transfer coefficient between the basement wall and the surface of the ground

$U_{\text {floor }}$ : Average overall heat transfer coefficient at the basement floor.

The heat loss from floors, which are placed on the ground or slightly above, can be calculated by:

$$
\dot{Q}_{\text {floor on grade }}=U_{\text {grade }} p_{\text {floor }}\left(T_{\text {indoor }}-T_{\text {outdoor }}\right) \text {, }
$$

where $U_{\text {grade }}$ represents the rate of heat transfer from the slab per unit temperature

difference between the indoor temperature, $T_{\text {indor }}$ and the outdoor temperature, $T_{\text {outdoor }}$ and per unit length of the perimeter $p_{\text {floor }}$ of the building.

The heat loss through the floor of the building, when the crawl space temperature is known, can be calculated by:

$$
\dot{Q}_{\text {building floor }}=U_{\text {building floor }} A_{\text {floor }}\left(T_{\text {indoor }}-T_{\text {crawl }}\right) \text {, }
$$

where $U_{\text {building floor }}$ is the overall heat transfer coefficient for the floor.

\section{d) Heat transfer through windows}

Three regions are considered in the heat transfer process through windows: the center-of-glass, the edge-of-glass, and the frame regions. After adding the heat transferred at each region, the total heat transfer is: 


$$
\dot{Q}_{\text {window }}=\dot{Q}_{\text {center }}+\dot{Q}_{\text {edge }}+\dot{Q}_{\text {frame }}=U_{\text {window }} A_{\text {window }}\left(T_{\text {indoors }}-T_{\text {outdoors }}\right),
$$

with $U_{\text {window }}$, the overall heat transfer coefficient of the window.

\section{e) Solar heat gain of the building}

It is given by the sum of the transmitted solar radiation and the portion of the absorbed radiation that flows indoors. The fraction of incidental solar radiation entering through the glazing is called the solar heat gain coefficient (SHGC), bringing the total heat gained by that window to:

$$
\dot{Q}_{\text {solar, gain }}=S H G C \times A_{\text {glazing }} \times \dot{q}_{\text {solar, incident }},
$$

where $A_{\text {glazing }}$ is the glazing area of the window and $\dot{q}_{\text {solar,incident }}$, the solar heat flux incident on the outer surface of the window.

\section{f) Infiltration heat load and weatherizing}

Although it is uncontrolled, and represents a significant amount of energy loss, it is possible to account for it by the latent and sensible heat load;

$$
\begin{aligned}
& \dot{Q}_{\text {inf,sensible }}=\rho_{o} \operatorname{Cp} \dot{V}\left(T_{i}-T_{o}\right), \\
& \dot{Q}_{\text {inf,latent }}=\rho_{o} h_{f g} \dot{V}\left(T_{i}-T_{o}\right),
\end{aligned}
$$

where $\rho_{o}$ is the density of the outdoor air, $C_{p}$ is the specific heat of air, $V$ is the volumetric flow rate of air, and $T_{i}-T_{o}$ is the temperature difference between the indoor 
and outdoor air. Similarly, $h_{f g}$ is the latent heat of vaporization at the indoor temperature and $w_{i}-w_{o}$ is the humidity ratio difference between the indoor and outdoor air.

\subsubsection{Sol-air temperature}

The influence of the sun over the earth can be appreciated by recalling that the deep space temperature is $-270^{\circ} \mathrm{C}$ and the temperature on the planet would not be higher without this heat source. The outdoor temperature variation is governed by the incidental solar radiation and the thermal inertia of the earth, which regulates the solar energy stored in the ground, the atmospheric air, and the building structures during the day, and their slow release at night. In the designed cooling load of a building, solar radiation plays a major role, considering that the peak usually occurs early in the afternoon as a consequence of the solar energy gain through glazing and from walls and roofs by absorption, which is then released later in the day.

The solar effect from the glazing, as was mentioned, can be accounted by the solar heat gain factor (SHGF). In opaque surfaces, such as roofs and walls, the solar energy can be conveniently accounted for by considering the outside temperature to be a higher amount, which provides the solar radiation effect. Applying this procedure in the heat transfer relations, the ambient temperature is replaced by a new sol-air temperature, which can be defined as the equivalent outdoor air temperature that gives the same rate of heat flow to a surface as would the combination of incident solar radiation, convection with the air, radiation exchange with the sky and the surrounding surfaces.

Heat transfer over a building surface subjected to solar radiation can be calculated by: 


$$
\begin{aligned}
& \dot{Q}_{\text {surface }}=\dot{Q}_{\text {conv }+ \text { rad }}+\dot{Q}_{\text {solar }}-\dot{Q}_{\text {radiation correction }} \\
& \dot{Q}_{\text {surface }}=h_{o} A\left(T_{\text {ambient }}-T_{\text {surface }}\right)+\alpha_{s} A \dot{q}_{\text {solar }}-\varepsilon A \sigma\left(T_{\text {ambient }}^{4}-T_{\text {surr }}^{4}\right),
\end{aligned}
$$

where $\alpha_{s}$ is the solar absorptivity and $\varepsilon$ is the emissivity of the surface. The solar radiation incident on the surface is given by the second term on Equation 3.12. Moreover, the heat transfer coefficient $h_{o}$ represents the combined heat transfer coefficient for convection and radiation:

$$
h_{o}=h_{\text {conv }}+h_{\text {rad }} \text {. }
$$

In equation (3.12), the first term represents the convection and radiation heat transfer to the surface when the average surrounding surface and sky temperature is equal to the ambient air temperature; the last term is the correction when these temperatures are different; similarly, the last term in the sol-air equation corresponds to this change (which ranges from 0 to $4^{\circ} \mathrm{C}$ ) and basically occurs due to the low effective sky temperature, depending if the roof is horizontal or inclined.

Defining the sol-air temperature as [1]:

$$
T_{\text {sol-air }}=T_{\text {ambient }}+\frac{\alpha_{s} \dot{q}_{\text {solar }}}{h_{o}}-\frac{\varepsilon \sigma\left(T_{\text {ambient }}^{4}-T_{\text {surr }}^{4}\right)}{h_{o}} .
$$

After replacing Equation 3.14 in Equation 3.12, the heat flux over the surface is given by:

$$
\dot{Q}_{\text {surface }}=h_{o} A\left(T_{\text {sol-air }}-T_{\text {surface }}\right) \text {. }
$$

From Equation 3.14, the sol-air temperature depends on the absortivity of the surface, as shown in Section 3.3.3. Figure 2 shows how the radiation effect is accounted for by increasing the ambient temperature. 

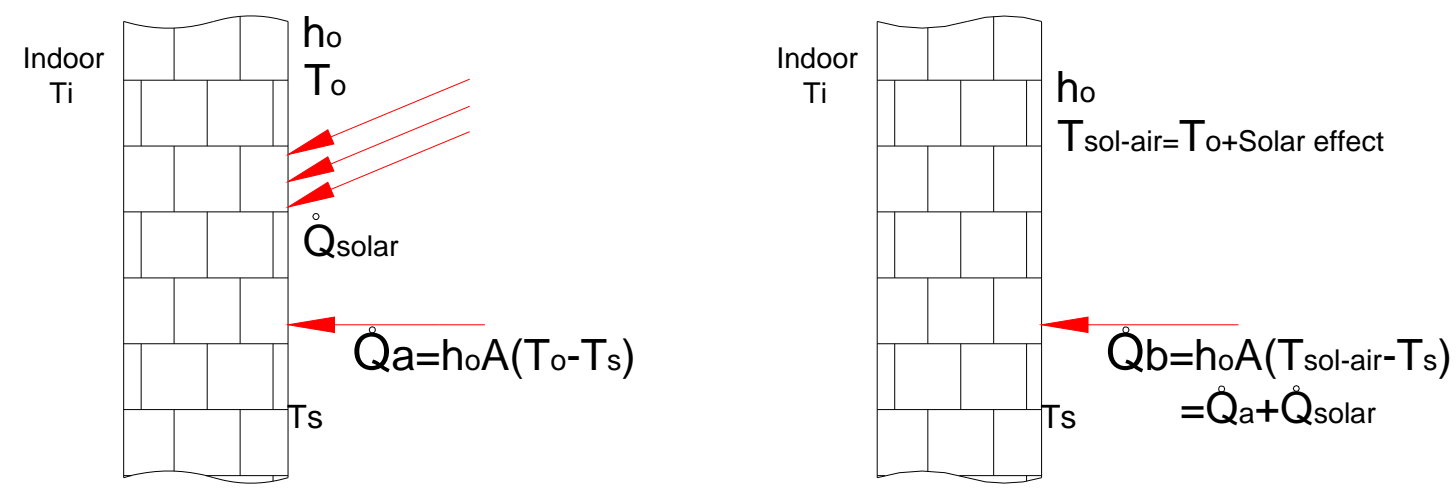

Figure 2. Effect of the sun-air temperature replacing the convection and radiation effect over the wall

\subsubsection{Heat transfer mechanism through walls}

Considering one-dimensional heat transfer through a simple or composite body, exposed to convection from both sides with mediums at temperatures $T_{\infty 1}$ and $T_{\infty 2}$, the total energy transferred can be calculated [43] by:

$$
\dot{Q}=\frac{T_{\infty 1}-T_{\infty 2}}{R_{\text {total }}},
$$

where $R_{\text {total }}$ is the total thermal resistance between the two mediums, and in this case is determined from:

$$
R_{\text {total }}=R_{\text {conv }, 1}+R_{\text {wall }}+R_{\text {conv }, 2}=\frac{1}{h_{1} A}+\frac{1}{k A}+\frac{1}{h_{2} A} .
$$

Figure 3 shows the thermal network method used in the last equation, which could be applied in walls consisting of two or more layers by adding the corresponding thermal resistances. 


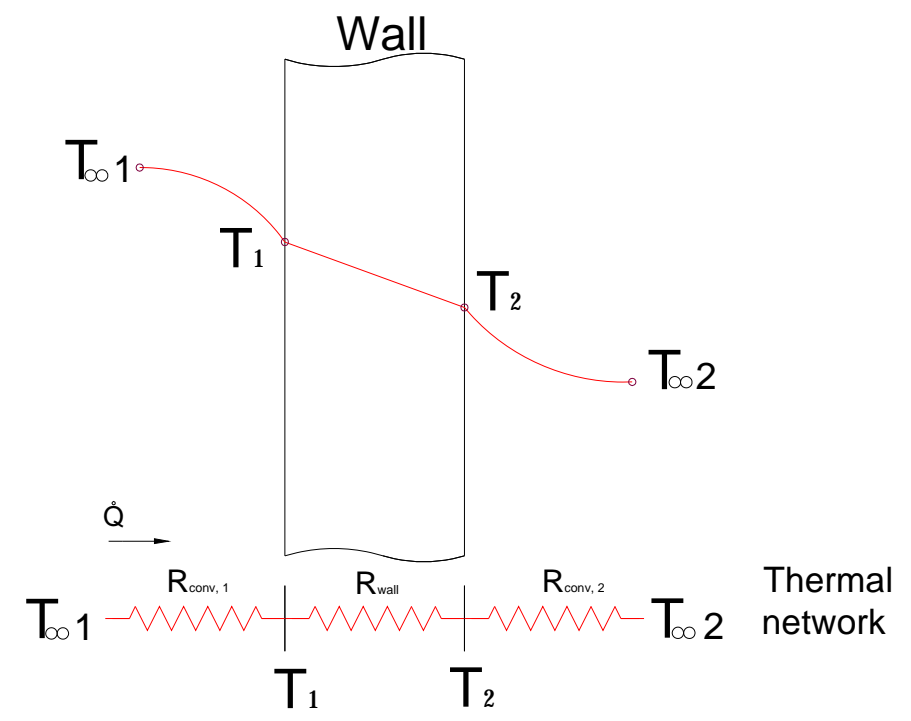

Figure 3. Thermal resistance networks through a plane wall

\subsubsection{Heat transfer through attics}

The thermal calculations of the attic depends on if it is ventilated or not. In the summer, the temperatures inside can approach the outside temperature (having a well vented attic), but it is still necessary to account for the heat radiation transferred to the ceiling from the roof.

For unventilated attics, heat transfer occurs through the closed system composed by the ceiling, the attic space and the roof. In order to calculate the R-value of the roofceiling system, it is necessary to combine the effects of the R-value of the ceiling, the Rvalue of the roof, and the thermal resistance of the space. A practical approach for this is calculating first the R-value of the ceiling and roof separately, using resistance networks, and considering the still-air case for the attic surfaces. After that, the following relation expresses the overall R-value of the ceiling-roof combination per unit area of the ceiling [1]: 


$$
R=R_{\text {ceiling }}+R_{\text {roof }}\left(\frac{A_{\text {ceiling }}}{A_{\text {roof }}}\right) .
$$

The last term in Equation 3.18 illustrates the influence of the attic geometry in the Rvalue of the system.

\subsection{Current roof model}

Figure 4 shows a typical tilted roof and a horizontal ceiling, containing an unventilated attic between them, frequently used to deal with rain and snow.

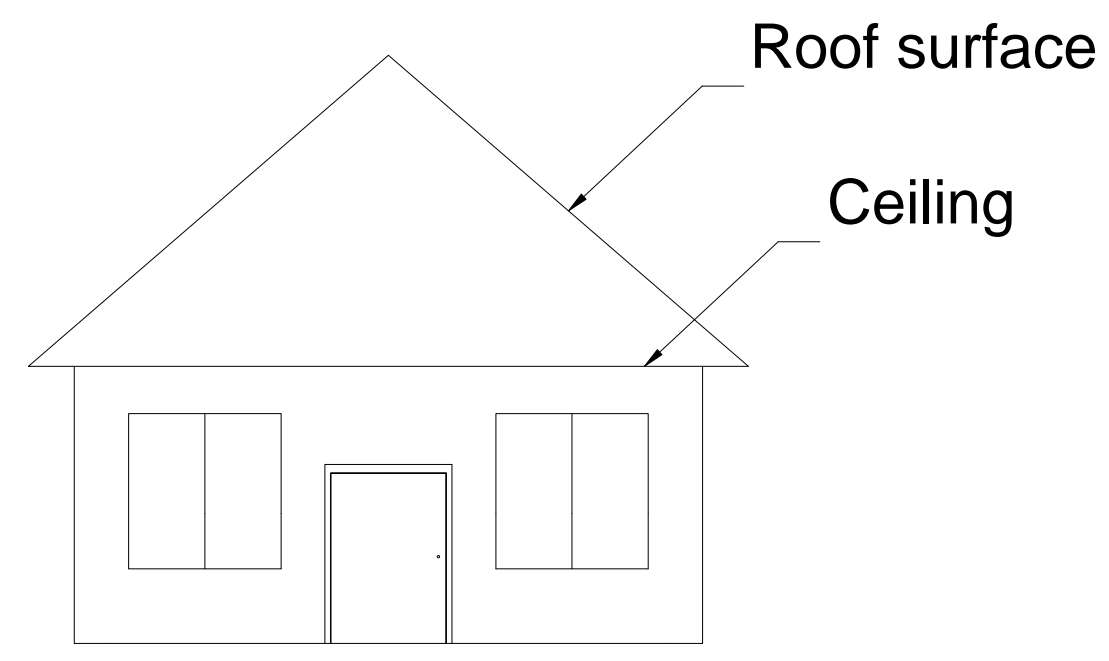

Figure 4. Typical tilted roof

The materials and corresponding R-values of the roof and the ceiling surfaces are shown in Tables 1 and 2 [1]: 
Table 1. Roof components and R-Value

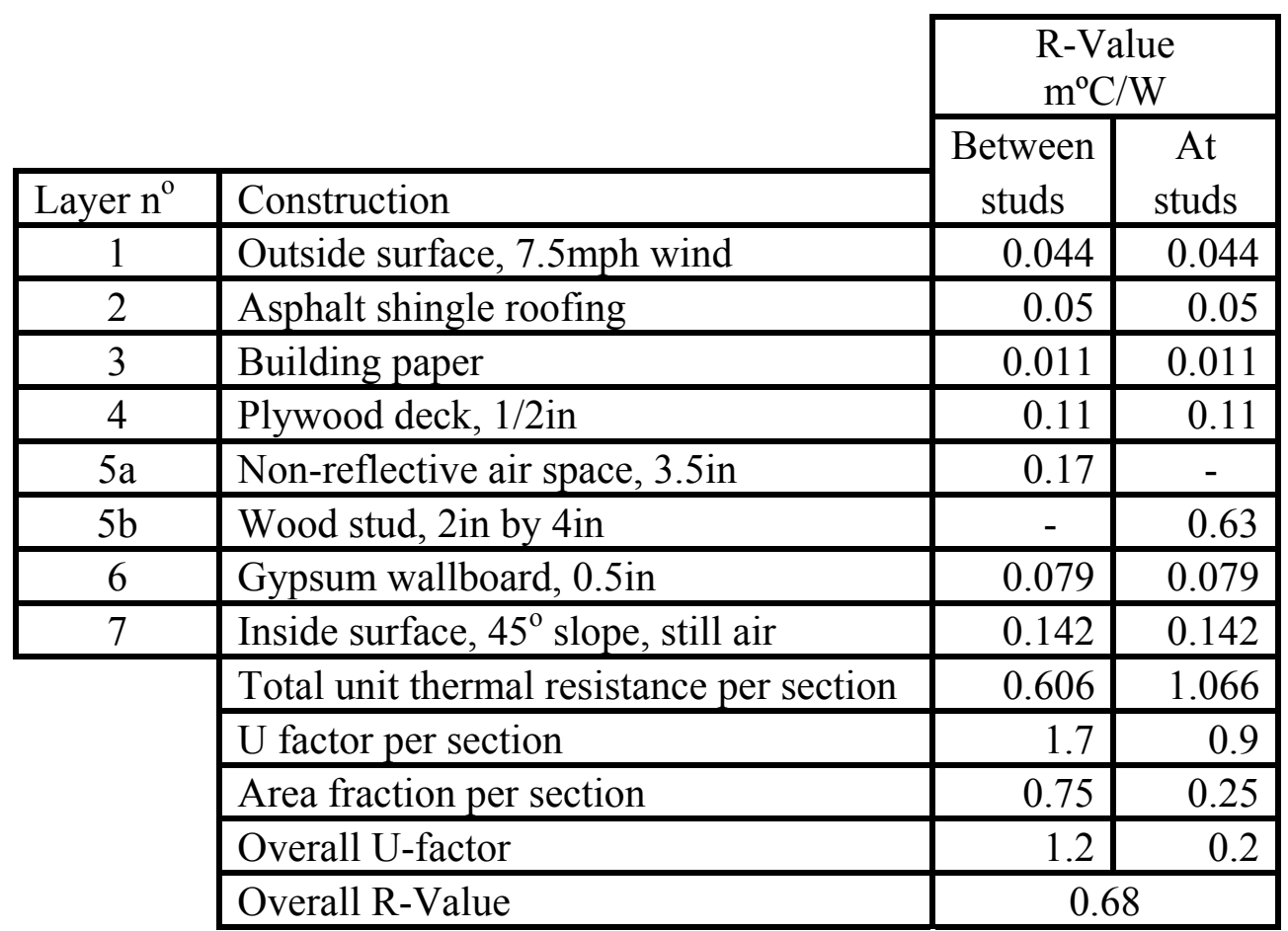

Table 2. Ceiling components and R-Value

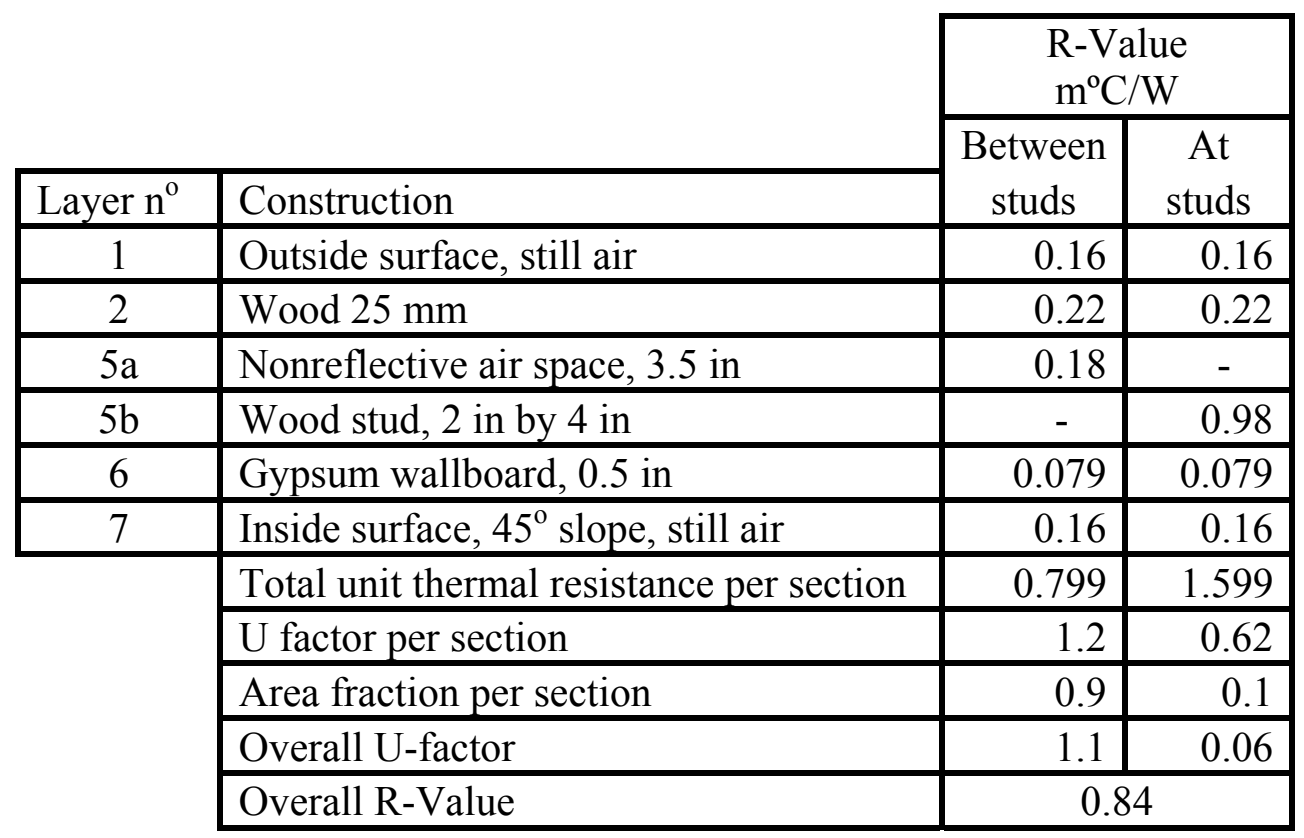


The thermal resistance of the inner surfaces and the non-reflective air space varies with the slope angle. Despite that different angles were considered, this effect has been neglected since its influence in the overall R-value is around $\pm 0.03 \mathrm{~m}^{2} \mathrm{C} / \mathrm{W}$. The overall R-value were considering according to Equation 3.17.

\subsection{Proposed roof model}

\subsubsection{Proposed roof description}

The double skin tilted roof, provided by a vertical extension, is shown in Figure 5. The materials selected are those of the previous model, considering the two upper surfaces made of the same material.

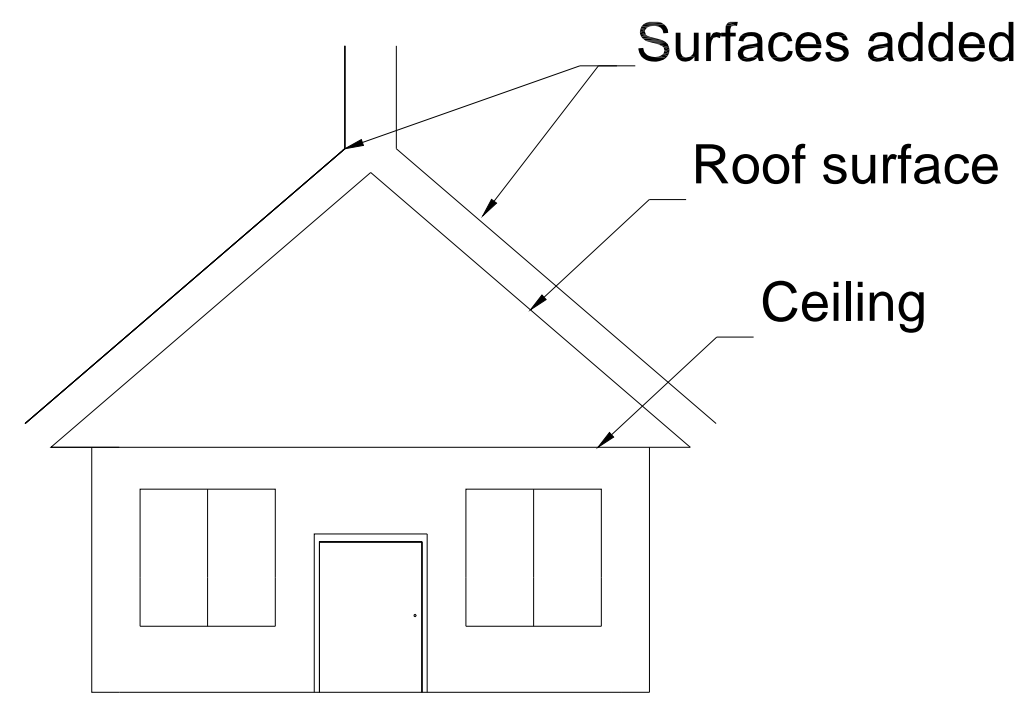

Figure 5. Proposed roof model

Then, the natural convection process, taking place in the channel between the roof and the surface, is added to the discussion. 


\subsubsection{Governing equations of the natural ventilation process}

\section{The natural ventilation process}

Natural convection heat transfer occurs when fluid at rest or with very low velocity is in contact with a surface at different temperature; in that, heat is transferred by conduction throughout adjacent layers. When the surface temperature is greater than the surrounding temperature, heat fluxes from the solid to the fluid. At a constant pressure, density decreases as temperature increases and buoyancy forces move the fluid particles up along the plate. The motion is maintained by the continual replacement of the heated air in the vicinity of the wall by the cooler air nearby.

\section{Buoyancy force}

This force is placed in a gravitational field as a force that pushes a fluid in a body completely or partially immersed. It can be described as:

$$
F_{\text {buoyancy }}=\rho_{\text {fluid }} g V_{\text {body }} \text {. }
$$

In addition, the net force acting on a body relates to its weight:

$$
\begin{aligned}
& F_{\text {net }}=W-F_{\text {buoyancy }} . \\
& F_{\text {net }}=\left(\rho_{\text {body }}-\rho_{\text {fluid }}\right) g V_{\text {body }} .
\end{aligned}
$$

This relation, known as the Archimede's principle, is proportional to the density difference of the fluid and the body immersed in it. In natural convection, this body-fluid relation is given by the lighter and the heavier fluid particles with their corresponding densities. 


\section{Volume expansion coefficient}

Since for this investigation temperatures are crucial, expressing the variables involved in the phenomenon in terms of temperature will be necessary. An important variable that relates density and temperature at a constant pressure is the volume expansion coefficient $\beta$, defined as:

$$
\beta=-\frac{1}{\rho}\left(\frac{\partial \rho}{\partial T}\right)_{p}
$$

\section{Boundary Layer equations}

The effect of the surface (i.e. a wall surrounded by air) producing fluid movement by warming it up is restricted to a thin region close to the wall, which thickness or 'thermal layer' is limited to the distance from the wall at which the temperature has dropped to a certain percentage of the outer temperature (e.g. 1\%). This thickness grows in the flow direction. Due to the natural convection motion, depending on the influence of

the heated wall over the air, the fundamental equations that relate its behavior are the boundary layer equations [44]:

$$
\begin{aligned}
& \frac{\partial}{\partial x}(\rho u)+\frac{\partial}{\partial y}(\rho v)=0, \\
& \rho\left(u \frac{\partial u}{\partial x}+v \frac{\partial u}{\partial y}\right)=-\rho g \sin \alpha-\frac{d p}{d x}+\frac{\partial}{\partial y}\left(\mu \frac{\partial u}{\partial y}\right), \\
& \rho C_{p}\left(u \frac{\partial T}{\partial x}+v \frac{\partial T}{\partial y}\right)=\frac{\partial}{\partial y}\left(\lambda \frac{\partial T}{\partial y}\right)+\beta T u \frac{\partial p}{\partial x}+\mu\left(\frac{\partial u}{\partial y}\right)^{2}
\end{aligned}
$$


In Figure 6, the velocity profile developed between two plates, heated by different loads, is shown. This profile follows the equations described above [45].

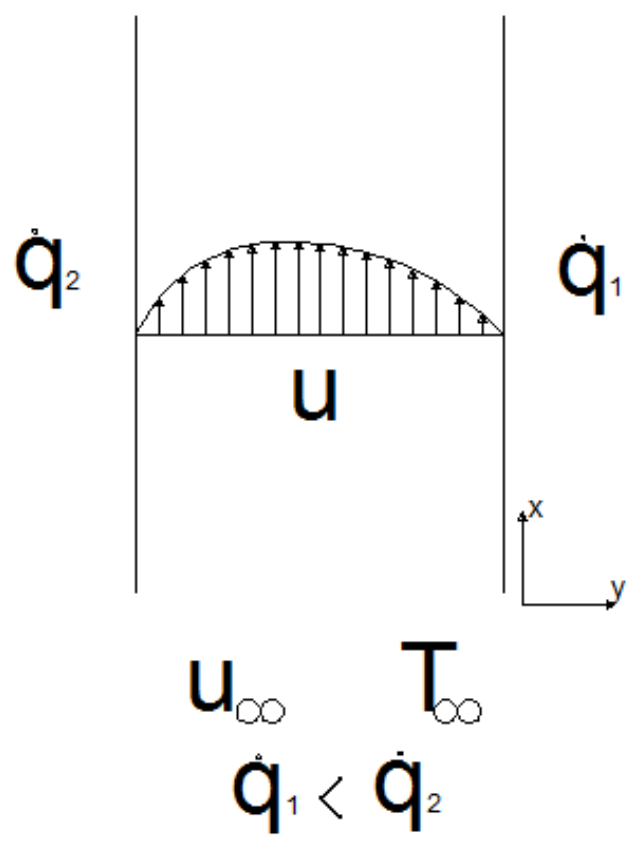

\section{Figure 6. Velocity profile in the channel}

If $p_{\text {stat }}$ is the pressure obtained at a particular elevation in the channel, considering the temperature uniform at $T_{\infty}$ through the flow field, thus;

$$
\frac{\partial p_{\text {stat }}}{\partial x}=-\rho_{\text {stat }} g \sin \alpha
$$

Then, the body and pressure forces can be combined to get:

$$
-\rho g \sin \alpha-\frac{\partial p}{\partial x}=-\left(\rho-\rho_{\infty}\right) g \sin \alpha,
$$

where $\rho_{\infty}=\rho_{\text {stat }}$ is related to the static field away from the wall at constant $T_{\infty}$.

Now, a crucial situation must be pointed out. Natural convection is based on the difference in densities present in the fluid (in this case air); it cannot occur at a constant 
density, and being an effect of variable properties, the momentum and energy equation end up mutually coupling. Next, under only small temperatures differences between fluid and surface or small wall heat fluxes, the following approximation is valid [44]:

$$
\rho(T)=\rho_{\infty}-\beta_{\infty} \rho_{\infty}\left(T-T_{\infty}\right)+\ldots
$$

This is the density function expanded in a Taylor series, with $\rho_{\infty}$ and $\beta_{\infty}$ evaluated at $T_{\infty}$. Breaking off the series after the linear term, and combining with Equation 3.26, yields:

$$
-\rho g \sin \alpha-\frac{\partial p}{\partial x}=\rho_{\infty} g \beta_{\infty}\left(T-T_{\infty}\right) \sin \alpha .
$$

Using other linear expansions, physical properties like viscosity can be approximated by:

$$
\mu(T)=\mu_{\infty}\left[1-K_{\mu} \frac{\Delta T}{T_{\infty}} v\right],
$$

with $v=\frac{\left(T-T_{\infty}\right)}{\Delta T}$, and $\Delta T$ is a characteristic temperature difference.

\section{Boussinesq approximation}

This approximation considers the limiting case $\Delta T / T_{\infty} \rightarrow 0$ in Equation 3.29, reducing all physical properties to their values at $T_{\infty}$. Density is evaluated at $T_{\infty}$ as well, with the exception of the buoyancy force term where it is evaluated, according to Equation 3.26. Once more, this approximation would be accurate as long as changes in actual density are small, specifically when $\beta\left(T-T_{0}\right)<<1$.

\section{Basic equations for natural convection in channels}

Finally, the basic equations for natural convection along the channel, according to the considerations developed above, are given by: 


$$
\begin{aligned}
& \frac{\partial u}{\partial x}+\frac{\partial v}{\partial y}=0, \\
& u \frac{\partial u}{\partial x}+v \frac{\partial u}{\partial y}=v_{\infty} \frac{\partial^{2} u}{\partial y^{2}}+g \beta_{\infty}\left(T-T_{\infty}\right) \sin \alpha, \\
& u \frac{\partial T}{\partial x}+v \frac{\partial T}{\partial y}=a_{\infty}\left(\frac{\partial^{2} T}{\partial y^{2}}\right),
\end{aligned}
$$

with $a_{\infty}=\lambda_{\infty} / \rho_{\infty} C p_{\infty}$ in Equation 3.32. Since velocities in natural convection flows are

very small, the dissipation term $\mu_{\infty}(\partial u / \partial y)^{2} / \rho_{\infty} C p_{\infty}$ has been neglected. These equations are applied to the vertical extension as well, with the corresponding value for $\alpha=90$.

\section{Grashof Number}

The natural convection flow regime can be assessed by the dimensionless Grashof number, which relates the buoyancy and viscous forces participating in the fluid:

$$
G r=\frac{\text { buoyancy forces }}{\text { viscuos forces }}=\frac{g \Delta \rho V}{\rho v^{2}}=\frac{g \beta \Delta T V}{\rho v} \text {, }
$$

or commonly expressed as:

$$
G r=\frac{g \beta\left(T_{W}-T_{\infty}\right) L^{3}}{v^{2}}
$$

where,

$T_{W}:$ Temperature at the wall,

$T_{\infty}:$ Temperature of the free flow, and

$v$ : Kinematic viscosity. 
The role that the Grashof number plays in natural convection is similar to the Reynolds number in forced convection, providing the same criteria in determining whether the flow is laminar or turbulent. For example, considering vertical plates, the critical Grashof number is observed to be around $10^{9}$, which means that for a Grashof number greater than this value, the flow regime becomes turbulent.

\section{Natural convection correlations}

Due to the complexities of the fluid motion in natural convection, solving the governing equations of motion and energy is very difficult. The analytical solutions that are known lack generality because they have been found under simplifying assumptions and applied for simple geometries, whereas most problems are studied by using experimental studies and correlations. From the simpler empirical correlations, the average Nusselt number is given [1] by:

$$
N u=\frac{h L}{k}=C(G r \operatorname{Pr})^{n}=C R a^{n}
$$

where Ra, the Rayleigh number, is the product of the Grashof and Prandtl numbers [1]:

$$
R a=G r \operatorname{Pr}=\frac{g \beta\left(T_{W}-T_{\infty}\right) L^{3}}{v^{2}} \operatorname{Pr},
$$

The value of $\mathrm{C}$ and $\mathrm{n}$ depend on the geometry of the surface and the flow regime characterized by the Rayleigh number range, which usually determines laminar flow when less than $10^{8}$, and transitions to turbulence between the range of $10^{8}<\mathrm{Ra}<10^{10}$. 


\subsubsection{Fluent setting}

Fluent was used as the solver of the governing equations previously discussed; the geometry and physical characteristic of the systems were earlier defined in Gambit.

\section{Solver used}

The chosen solver was the Surface to Surface radiation model (S2S). Despite not having considered properties such as emissivity, absorptivity or reflectivity as variables in the problem, the radiation heat transfer should be accounted for the overall heat load inside cavities.

\section{Temperatures at the indoor and outdoors locations}

The indoor condition was given by a room temperature value of $298 \mathrm{~K}$. The outdoor conditions were the corresponding to the higher temperature on a typical day in summer at latitude 40 , considering an absorptivity coefficient in the surface equal to 0.87 . According to ASHRAE, Handbook of Fundamentals, Ref 46, Chap 26, Table 1, the solair temperature and the ambient temperature under these conditions are $335 \mathrm{~K}$ and $308 \mathrm{~K}$, respectively.

The sol-air temperature varies with the angle of inclination and throughout the day. In order to compare the thermal response of the roofs under similar conditions, a constant sol-air temperature was considered at every tilt angle; then the evaluation has not necessarily done at the same time of the day for all the cases. 


\section{Physical properties and dimensions}

The physical properties were, in the case of the fluid, average values of air at temperatures between $35^{\circ} \mathrm{C}$ and $65^{\circ} \mathrm{C}$. Properties at the roof and ceiling surfaces were given according to the materials shown in Section 3.2. The geometric variables examined in this work are shown in Figure 7.

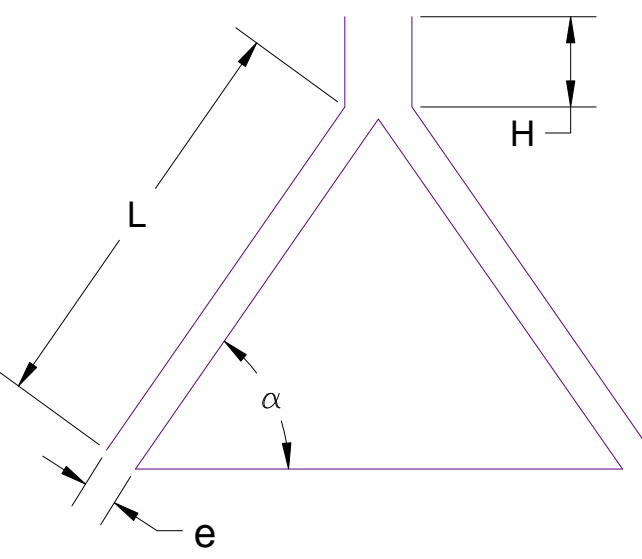

Figure 7. Variables involved in the proposed roof construction

The values of the variables shown above are summarized in Table 3.

Table 3. Dimensions used for the different cases

\begin{tabular}{|l|l|}
\hline Tilt angle: $\alpha$ & $30,45,60,65$ degrees \\
\hline Roof length: $\mathrm{L}$ & $2 \mathrm{~m}, 6 \mathrm{~m}$ \\
\hline Roof width & $1 \mathrm{~m}$ \\
\hline Channel width: e & $\begin{array}{l}0.02 \mathrm{~m} 0.05 \mathrm{~m}, 0.08 \mathrm{~m}, 0.10 \mathrm{~m}, 011 \mathrm{~m}, 0.13 \mathrm{~m}, 0.14 \mathrm{~m}, 0.15 \mathrm{~m}, \\
0.18 \mathrm{~m}\end{array}$ \\
\hline Vertical extension: $\mathrm{H}$ & $\begin{array}{l}0.25 \mathrm{~m}, 0.50 \mathrm{~m}, 0.70 \mathrm{~m}, 0.75 \mathrm{~m}, 0.80 \mathrm{~m}, 0.90 \mathrm{~m}, 1 \mathrm{~m}, 1.20 \mathrm{~m}, \\
1.5 \mathrm{~m}, 2 \mathrm{~m}, 2.3 \mathrm{~m}\end{array}$ \\
\hline Ceiling thickness & $0.215 \mathrm{~m}$ \\
\hline $\begin{array}{l}\text { Roof/upperoof } \\
\text { thickness }\end{array}$ & $0.15 \mathrm{~m}$ \\
\hline
\end{tabular}


Different combinations of the mentioned variables determine the cases evaluated. The vertical extension is related to the roof length $(\mathrm{L})$ according to the percentage which it represents on that; for example, at $\mathrm{H}=0.25 \mathrm{~m}$, and $\mathrm{L}=2 \mathrm{~m}$, the vertical extension is $12.5 \%$ of L.

\section{Boundary conditions}

\section{Current roof:}

The boundary conditions of the current roof model were defined as follows:

- Ceiling: convection heat transfer was specified in this zone. The heat transfer coefficient is the correspondence to still air above horizontal surfaces, with the heat flux going down, and according to ASHRAE, Handbook of Fundamentals, Ref 46, Chap 26, Table 1, it is equal to $6.13 \mathrm{~W} / \mathrm{m}^{2} \mathrm{~K}$. The free stream temperature as mentioned is $298 \mathrm{~K}$ and the wall thickness, $0.215 \mathrm{~m}$. This thickness in conjunction with the material conductivity determines the R-value previously found in Section 3.2.

- Roof: similar to the ceiling, convection heat transfer was considered in this region. The heat transfer coefficient at summer conditions for moving air is 22.7W/m² K (ASHRAE, Handbook of Fundamentals, Ref 46, Chap 26, Table 1). The free stream temperature is given by the sol-air temperature, previously discussed, which equals $335 \mathrm{~K}$. The corresponding wall thickness is $0.15 \mathrm{~m}$. 


\section{Proposed roof:}

In this model, the boundary conditions were defined similarly to the current roof in the ceiling and the roof (here called the upper roof). The lower roof, inlet and outlet regions were considered as follows:

- Lower roof: its value is coupled with the conditions specified. The corresponding $\mathrm{R}$-value is obtained by considering a wall thickness equal to $0.15 \mathrm{~m}$.

- Inlet and outlet: The pressure in these regions is atmospheric. Then according to:

$$
p^{\prime}=p_{s}-\rho_{\infty} g x
$$

where $\mathrm{p}_{\mathrm{s}}$ is the ambient pressure, $\mathrm{p}$ ' must be zero. This variable, known as the gauge pressure, is recognized by Fluent as the boundary pressure condition [47].

The boundary conditions applied at the different zones of the proposed roof model are graphically summarized in Figure 8:

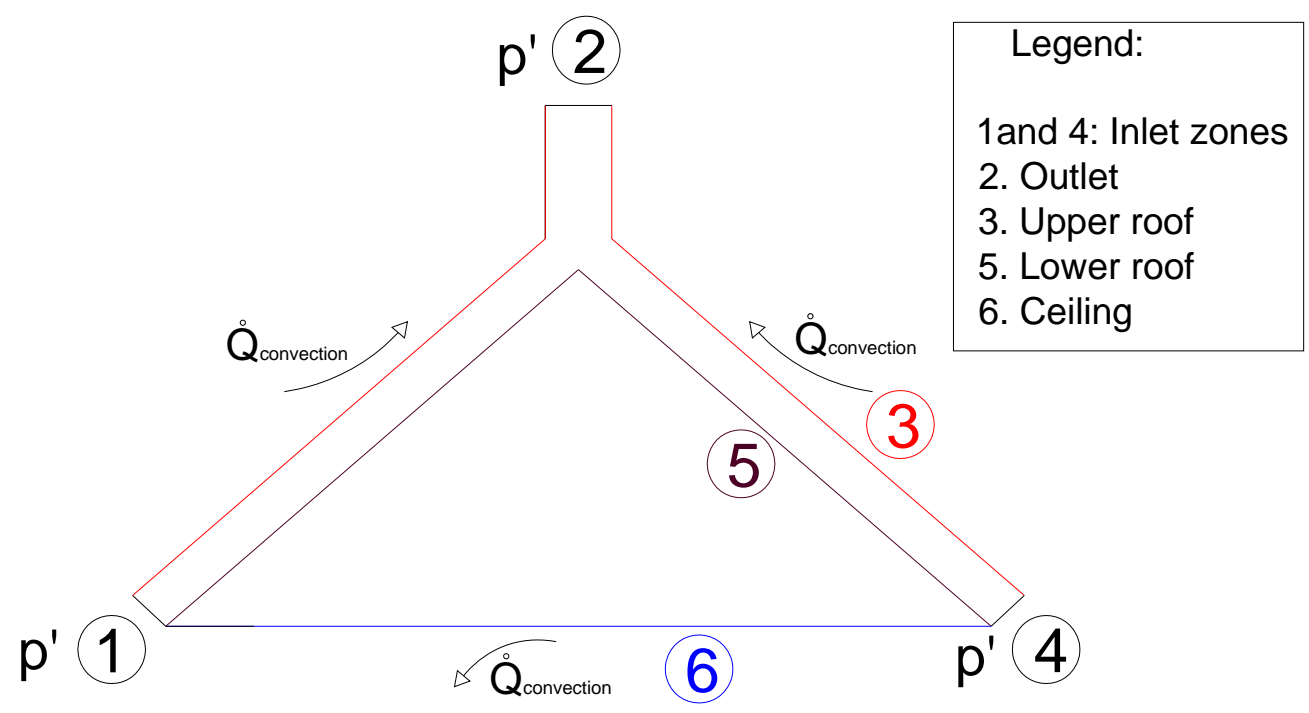

Figure 8. Proposed roof model sketch used in Fluent 


\subsubsection{Thermodynamic analysis}

The First Law of the Thermodynamics establishes that the energy balance of a system at steady conditions and in absence of internal generation of energy is given by:

$$
E_{\text {in }}=E_{\text {out }}
$$

Figure 9 shows the mass flow along the channel and the heat flux over the system formed by the upper roof, lower roof and the ceiling.

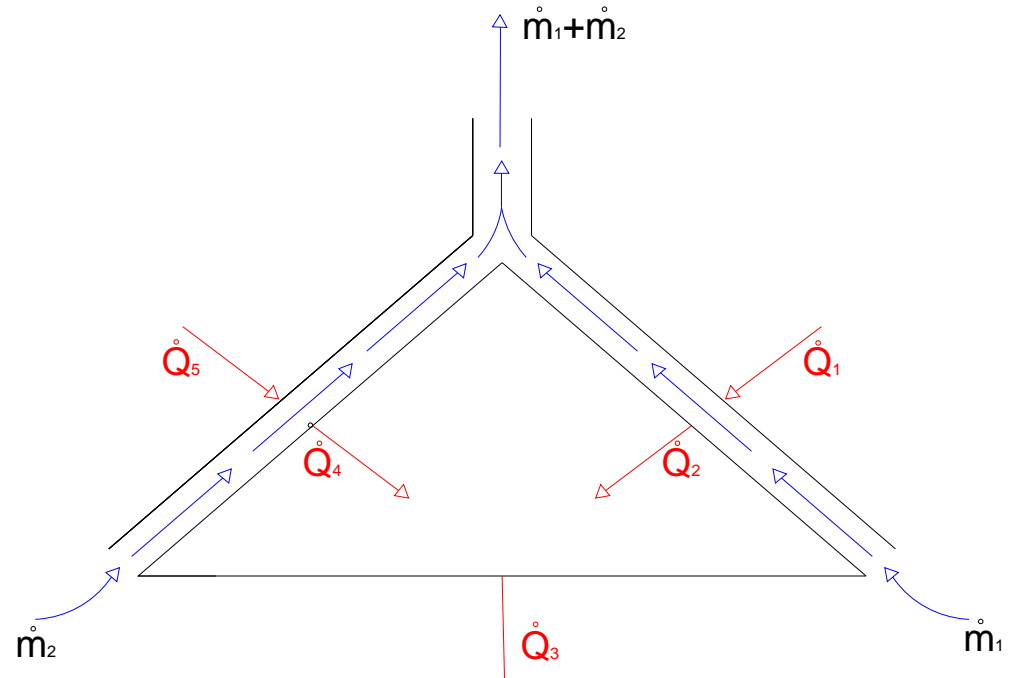

Figure 9. Heat load over the roof-attic-ceiling system

Since the channel is an open system, Equation 3.38 can be expressed as:

$$
Q_{1}+Q_{5}+\left(m_{1}+m_{2}\right) \Delta h=Q_{2}+Q_{4}=Q_{3}
$$

where $\Delta h$ is the difference of enthalpies between the outlet and inlets (both inlets are at the same temperature and pressure). Then, some of the heat load is driven off of the channel by the mass flow, and does not account for the attic-ceiling heat flux. 


\subsubsection{Validation}

The accuracy of the methodology employed in Fluent facing natural convection is contrasted with experiments where the phenomenon is treated under similar conditions.

W. Aung et al. [45] conducted an investigation analyzing natural convection in open channels. They studied two walls at constant temperatures, different than each other, and made of aluminum plates with dimensions 7 in. by 7 in. and a thickness $0.5 \mathrm{in}$. The hotter plate was heated using a water pool and the colder by circulating a water-oil mixture through a maze of grooves machined into the back of the plate. For visualization purposes, glass plates were clamped and sealed on the vertical edges of the isothermal plates. The channel widths were of six different lengths and varied from 0.18 in to $0.75 \mathrm{in}$.

Despite the vertical position, which is not the orientation used in the proposed roof model, the comparison reflects the accuracy of the surface-to-surface radiation model (S2S) analyzing natural convection in channels.

Two sets of experimental and numerical data are compared, the cases are specified by:

Ratio of temperature: $r_{t}=\frac{T_{2}-T_{0}}{T_{1}-T_{0}}$,

Grashof: $G r=\frac{g \beta\left(T_{1}-T_{0}\right) b^{4}}{l v^{2}}$, and

Rayleigh: $R a=\operatorname{Pr} * G r$.

Also, the dimensionless form of temperature and position along the channel are given by: 
Theta: $\theta=\frac{T-T_{0}}{T_{1}-T_{0}}$, and

Position: $Y=\frac{y}{b}$.

Comparison of the theta function distributions in the exit obtained from experimental and numerical methods are shown in Figure 10. Experiment 1 considered a ratio of temperatures equal to 0.51 and a Raleigh number of 14.20, while Experiment 2 is specified by 0.6 and 2.57 , respectively. The results obtained by the solver used in this investigation approximated that of the experimental data, with a less fluctuating behavior, then, the solver seems to be able to process natural ventilation along channels with reliability.
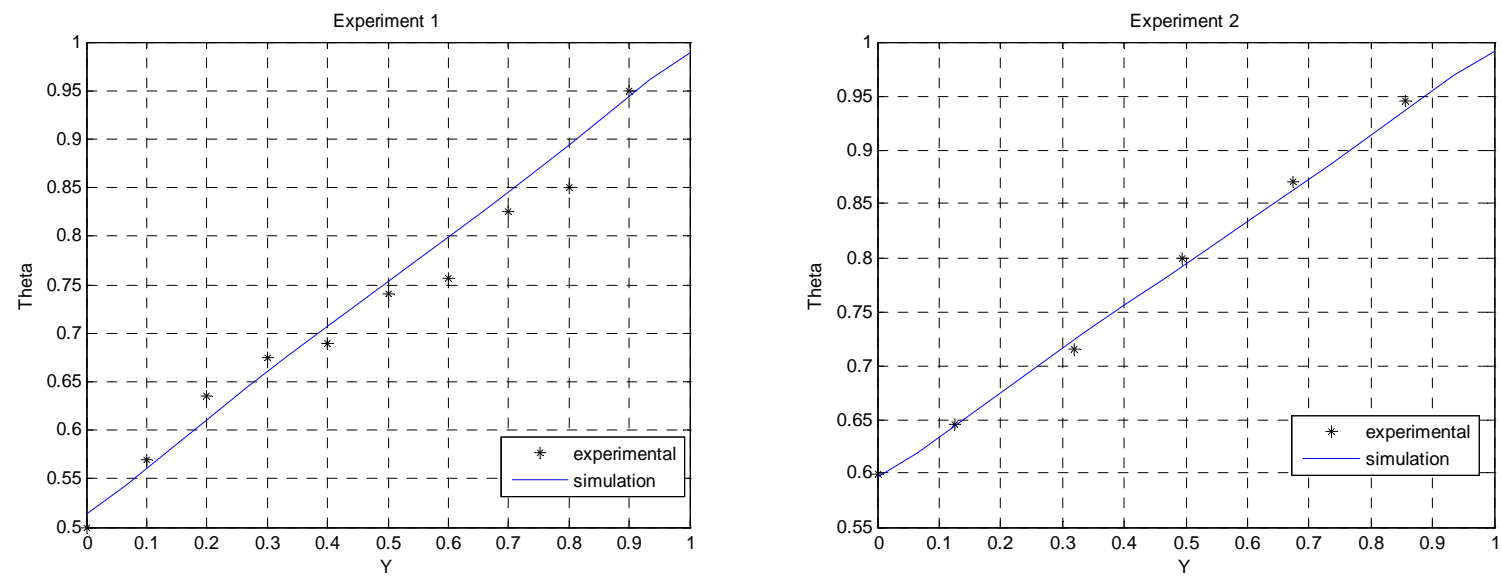

Figure 10. Comparison of data obtained from experimental and numerical methods

This chapter has synthesized the theoretical background and how the chosen methodology was established. The evaluation of the particular influence of the variables considered in the system is shown in the next chapter. 


\section{Chapter 4}

\section{Results and Discussion}

This chapter relates the behavior of the current roof model with the proposed model by comparing the thermal response to the conditions established. Since the heat flux through the ceiling determines the heat to be removed, the emphasis is given to this surface.

\subsection{Temperature distribution in the roof-ceiling system}

Comparisons of the temperatures reached in a typical roof (left side) and in the proposed roof (right side) for different tilt angles are shown in Figure 11, Figure 12 and Figure 13. In the proposed roof, a channel width of $0.05 \mathrm{~m}$ and vertical extension of $12.5 \%$ of the roof length $(2 \mathrm{~m})$ were considered.

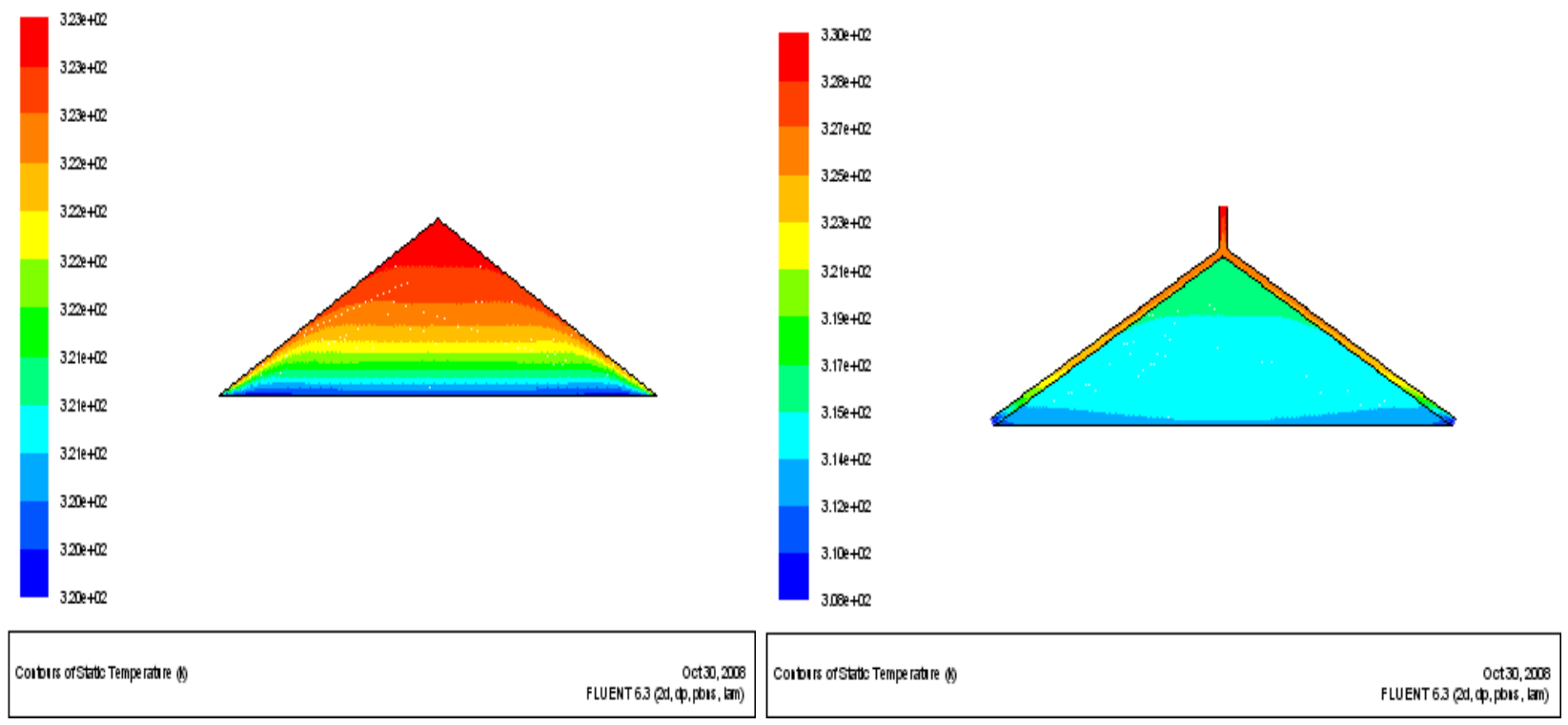

Figure 11. Temperatures distribution in the attic, tilt angle $30^{\circ}$ 

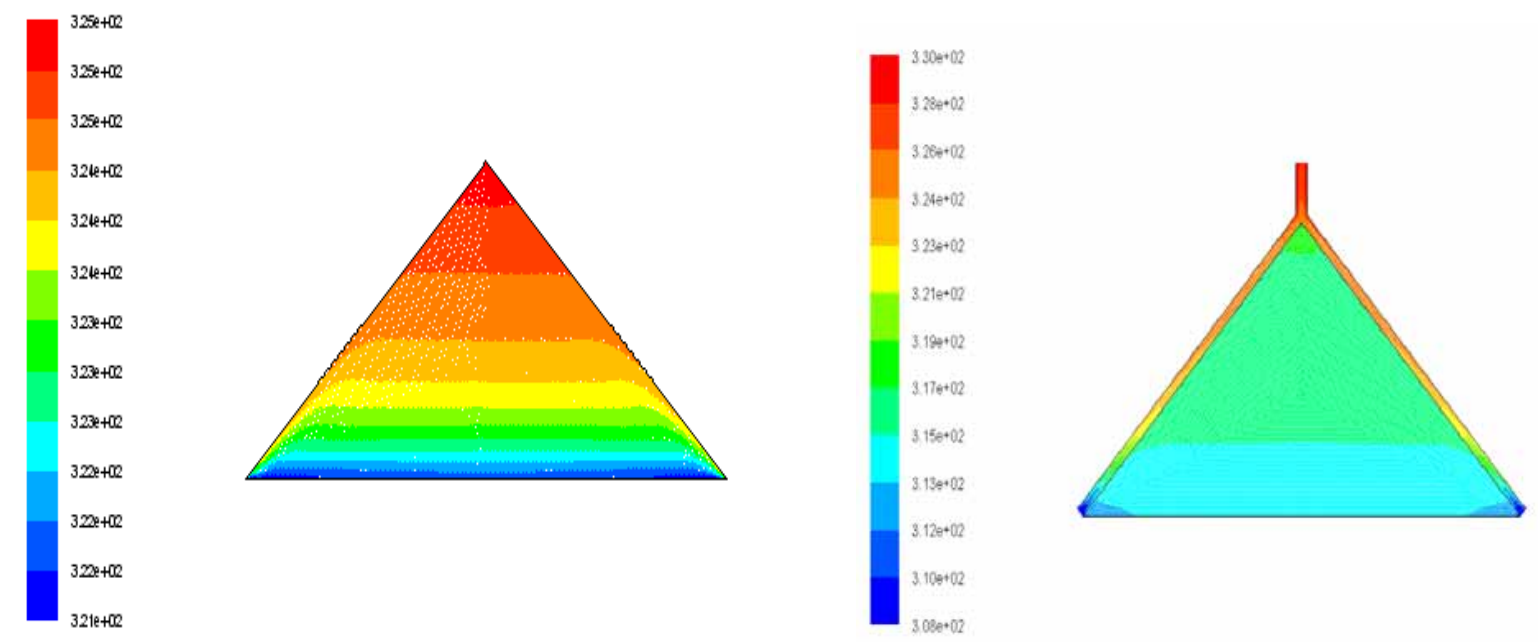

$321 e+10$

$1080 \cdot 12$

Figure 12. Temperatures distribution in the attic, tilt angle $45^{\circ}$
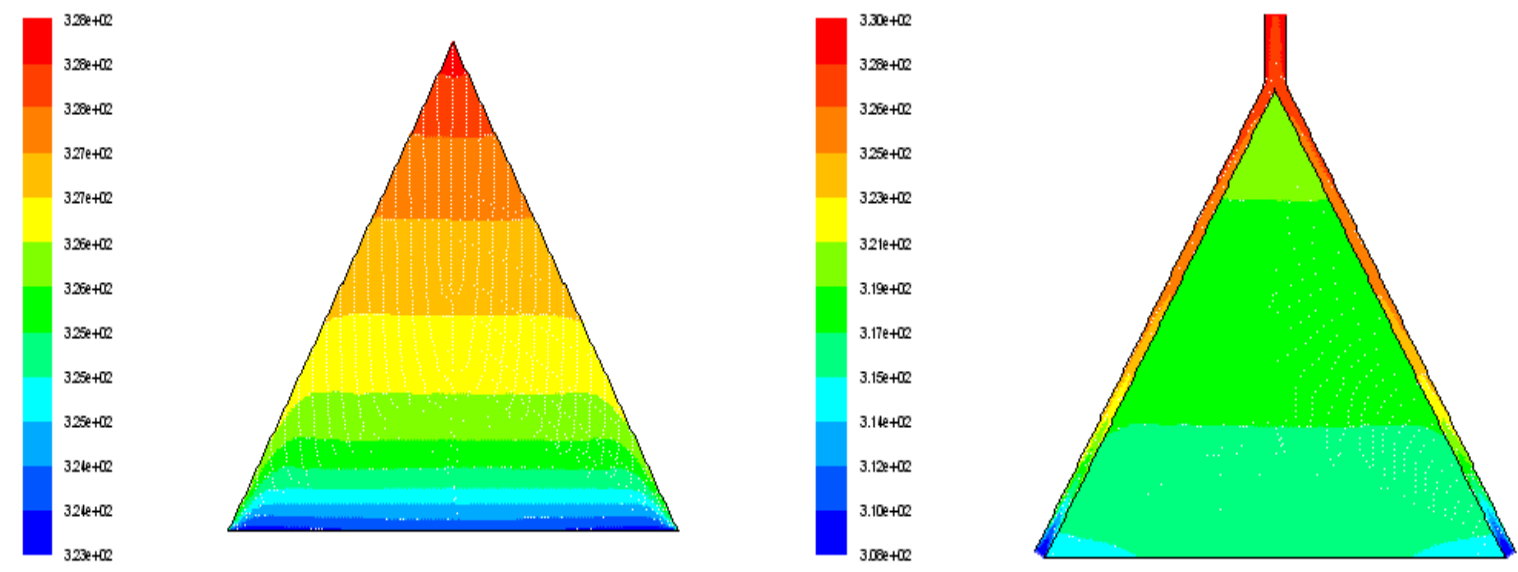

Figure 13. Temperatures distribution in the attic, tilt angle $60^{\circ}$

Despite every external surface undergoes the same heat transfer mechanisms, under similar outdoor and indoor temperatures and even made of the same material, different values of temperature distribution are developed along them. For example, looking at the current roof designs, the lower values of the tilt angle, the higher 
temperature in the exterior surface, and consequently in the ceiling surface. According to Equation 3.18, the R-value of the attic rises when the ratio of ceiling to roof area also increases. Since the roof area is constant in the three cases; the larger R-value is at $30^{\circ}$ of inclination. The increment of the resistance reduces the temperatures of the surfaces, due to the outdoor and indoor temperatures are fixed.

A sensible reduction in the temperature of the surfaces is appreciated when the current roof is provided with a natural ventilation system. The conditions under which it is possible to get a bigger reduction will be developed in the following sections.

\subsection{Velocity profiles in the channel exit}

Air is moved by buoyancy forces along the channel; the velocity magnitude of the flow at the inlet and outlet corresponding to a $0.05 \mathrm{~m}$ width of channel, $12.5 \%$ of vertical extension $(\mathrm{L}=2 \mathrm{~m})$ and a $30^{\circ}$ inclination is represented in Figure 14.
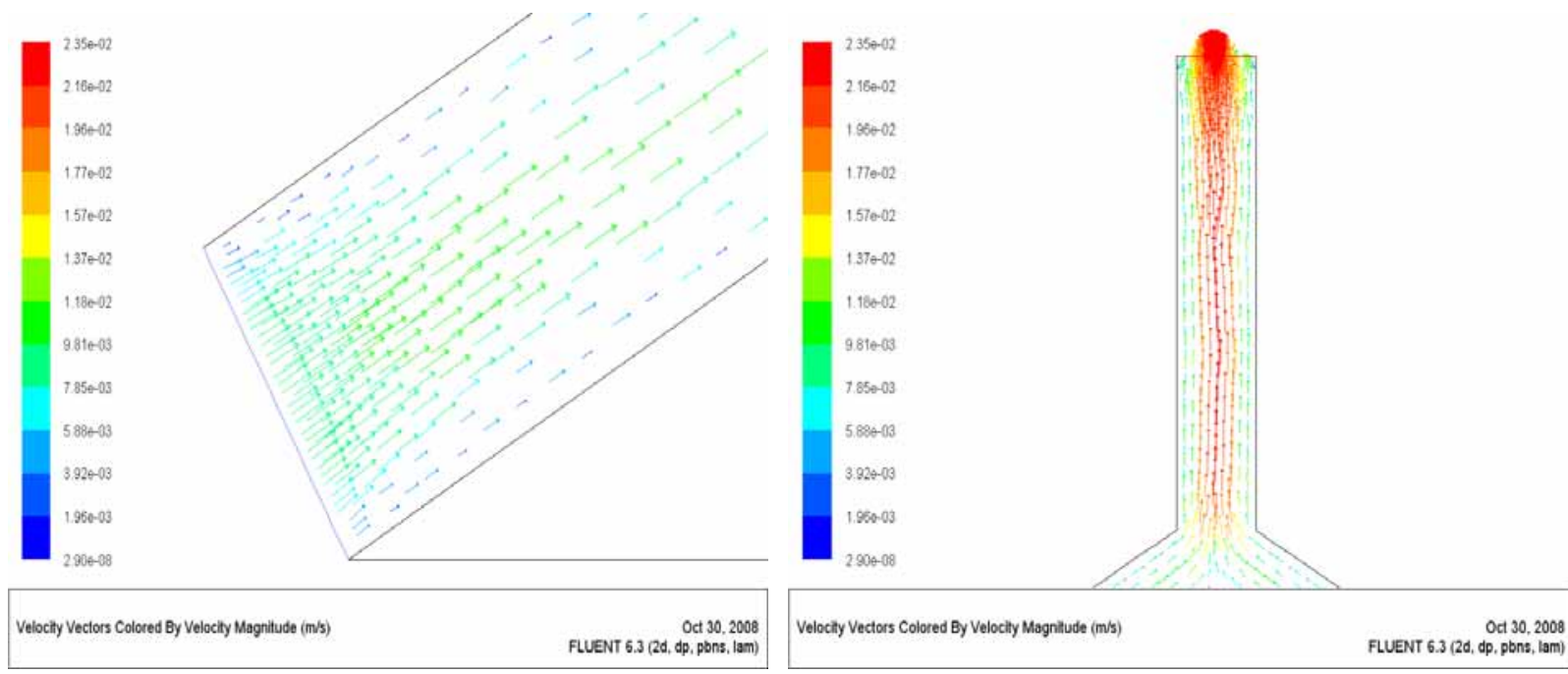

Figure 14. Velocity vectors in the inlet (left) and outlet (right) 
Here, the average velocity magnitude in the inlet and outlet zones is $8 \times 10^{-3} \mathrm{~m} / \mathrm{s}$ and $2.35 \times 10^{-2} \mathrm{~m} / \mathrm{s}$ respectively. The range of velocities is affected by the dimensions considered, i.e. at a vertical extension of $37.5 \%$ and $0.10 \mathrm{~m}$ of channel width, the range of velocities goes from $2.64 \times 10^{-2} \mathrm{~m} / \mathrm{s}$ at the inlet to $3.78 \times 10^{-2} \mathrm{~m} / \mathrm{s}$ at the outlet.

Velocity profiles at different angles and channel widths are shown in Figure 15. The velocity magnitudes do not increase considerably at different tilt angles (left). Actually, the major difference is in shape and it is due to the exit length, which grows when the tilt angle does (channel exit length was built according to $2 \times e \sin \alpha$ ). On the right, increasing of the channel width enlarges the velocity profile.
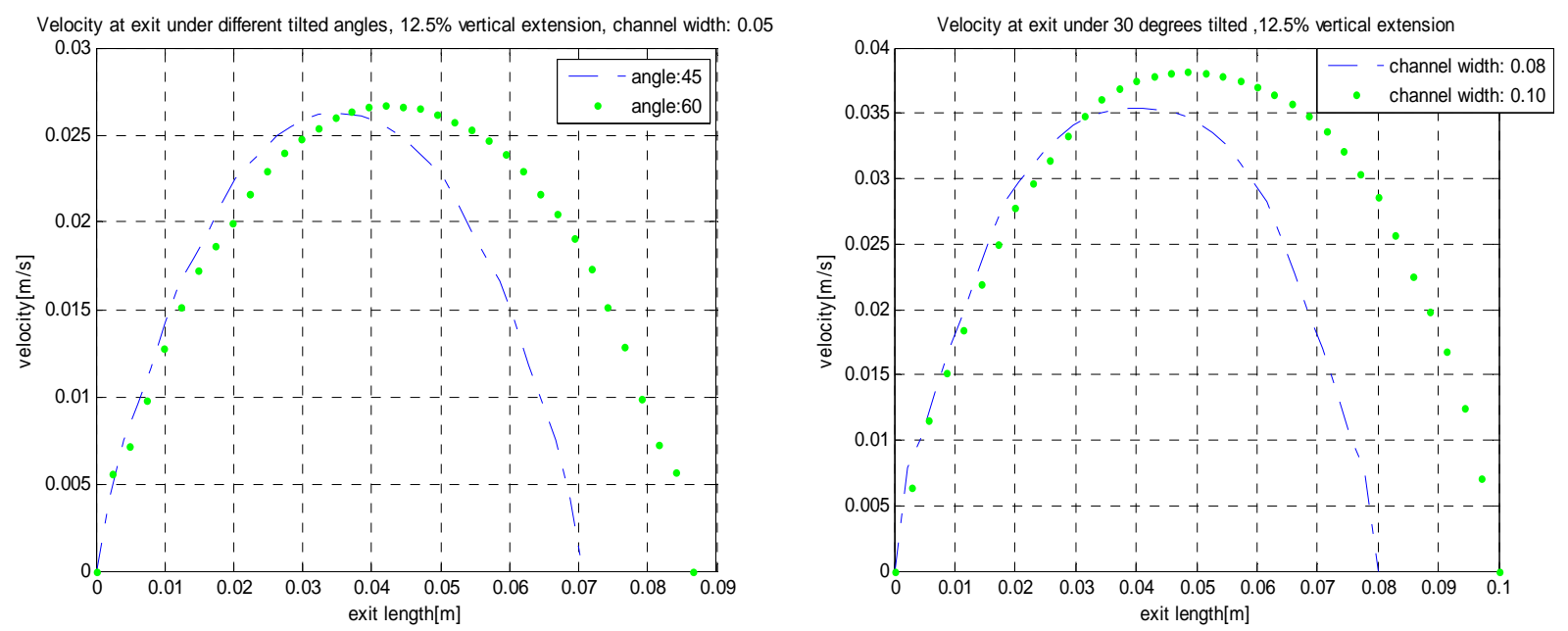

Figure 15. Velocity profiles in the outlet

Figure 16 shows the velocity profiles in the exit, considering $\mathrm{L}=2 \mathrm{~m}$. Here it is also appreciated how the velocity curves are smoother when the space between surfaces is bigger. The velocity profile is conditioned by the boundary layers adjacent to every heated wall and their superposition, since this is the region where the fluid particle acquires the energy to move. When the exit length is larger than $0.18 \mathrm{~m}$, the boundary 
layers are far from each other, and the velocity magnitude decreases in the middle of the cavity, where the fluid particle is away from the thermal boundary region.

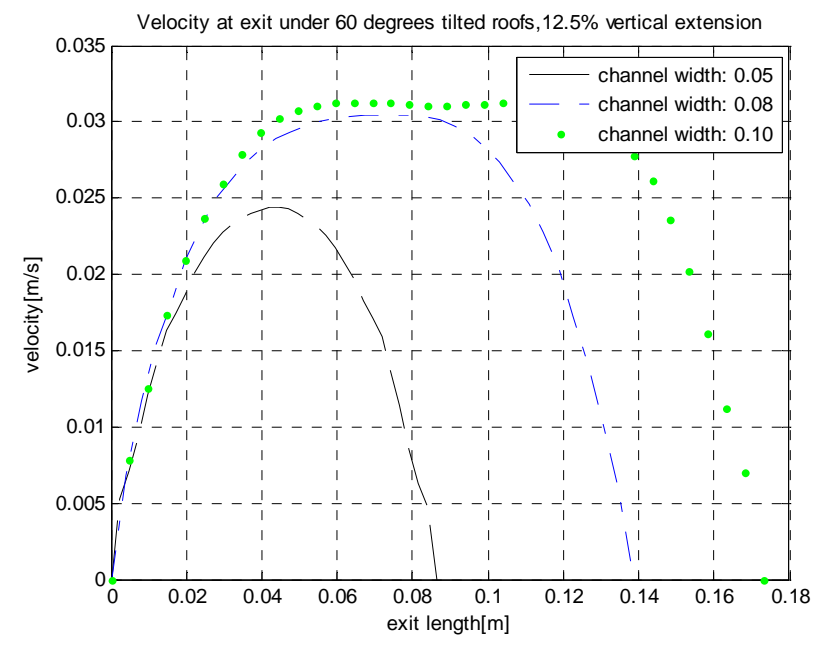

Figure 16. Velocity profiles in the exit, at $L=2 m$

The vertical extension also contributes to increasing the velocity magnitude. In Figure 17 , the velocity profile increases with $H$, due to the acceleration that the fluid particle experiences along the cavity, influenced by the gravity.

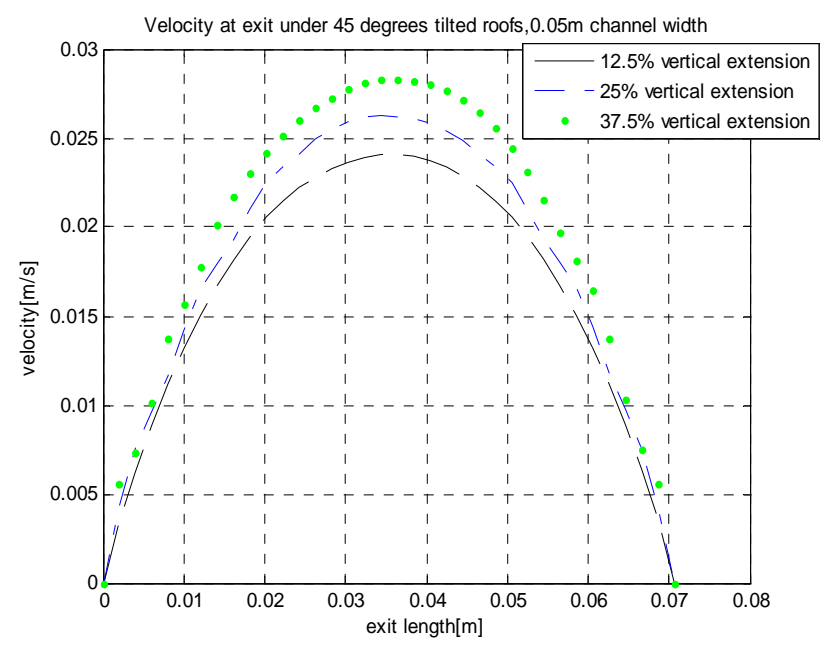

Figure 17. Velocity profile in the exit under 45 tilt angles 
The general shape of the velocity profiles is maintained at larger values of $\mathrm{L}$ but, as it could be expected, the velocity magnitude in this case is higher. Considering $\mathrm{L}=6 \mathrm{~m}$ (Figure 18), the influence of the vertical extension and the channel width is similar to that obtained at the smaller value of $\mathrm{L}$.
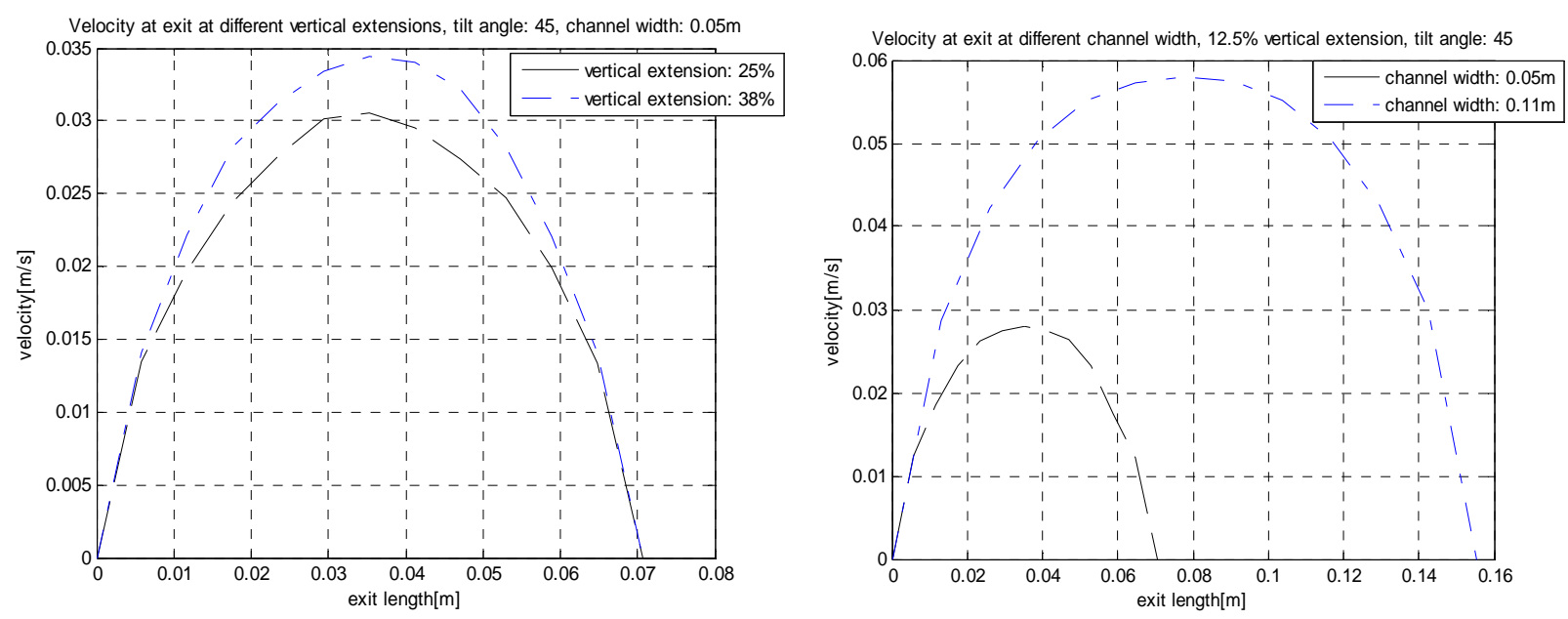

Figure 18. Velocity profiles in the exit at $\mathrm{L}=6 \mathbf{m}$

\subsection{Mass flow in the channel}

The mass flow relates the velocity and density of the air along the channel. In Figure 19, the mass flow variation not only reflects the conditions influencing the velocity magnitudes. As before, it increases with the increment of the vertical extension and channel width, however, a sensible increment is appreciated when the tilt angle is larger. This effect was not achieved in the velocity profiles, then it is inferred that the density influence is clearly enhanced by the tilt angle. 

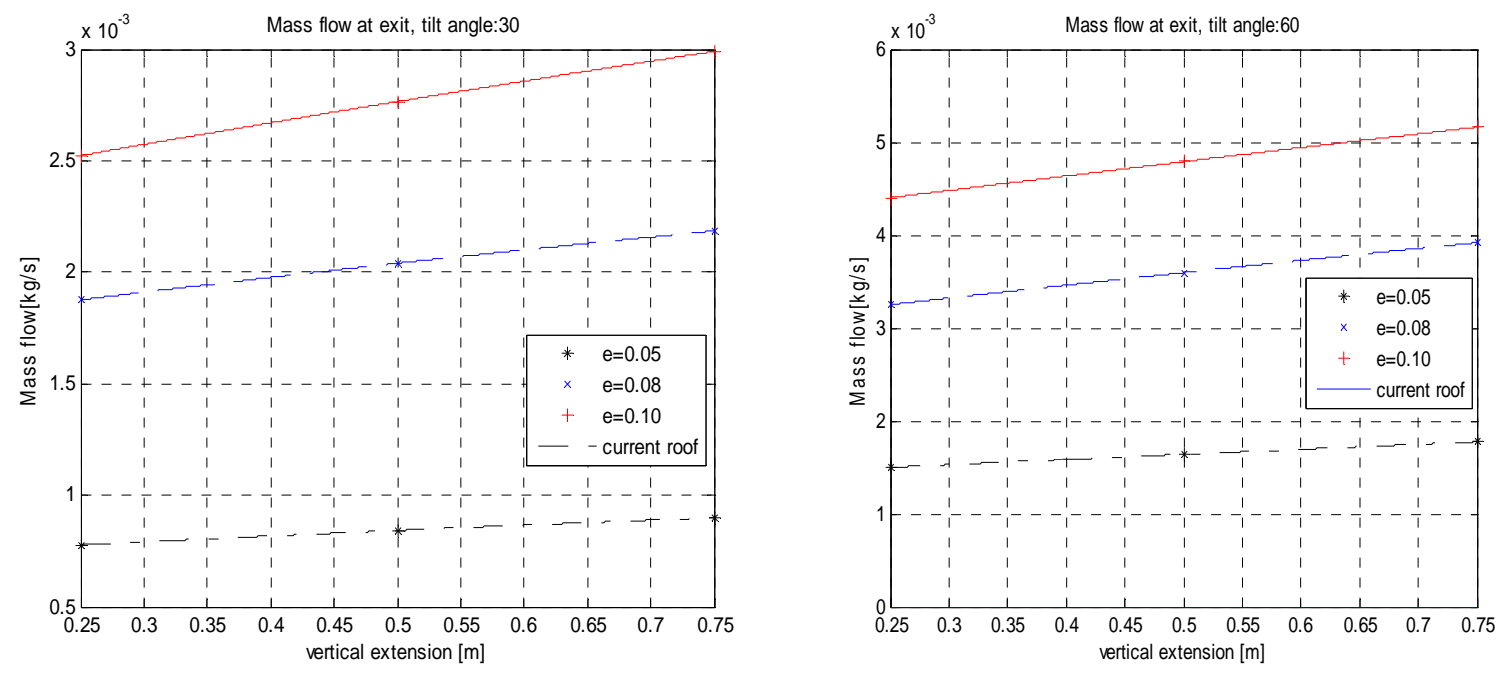

Figure 19. Mass flow along different channels, $L=2 m$

\subsection{Temperature of the ceiling}

\subsubsection{Influence of the tilt angle}

The effect of the tilt angle is related to the R-value of the attic in the current roof model. In the natural ventilation system, the tilt angle also influences the buoyancy force magnitude, since it is related to the gravitational acceleration and the vertical direction in which it acts, then, the conditions for cooling are improved at higher angles of inclination. Figure 20 shows the temperature distribution along the ceiling and how the temperatures decrease in the proposed model in comparison with the current design at different inclinations.

In addition, these temperature distributions show that the reduction gradient is steeper at the extremes. Radiation heat transfer is the mechanism that increases the temperature in the middle of the ceiling-roof enclosure, where due to their proximity; it should have been expected higher temperatures in the extremes as a consequence of heat 
transferred by conduction and convection. The angle of inclination affects radiation by modifying the geometry of the attic, and consequently, the view factor of the enclosure.
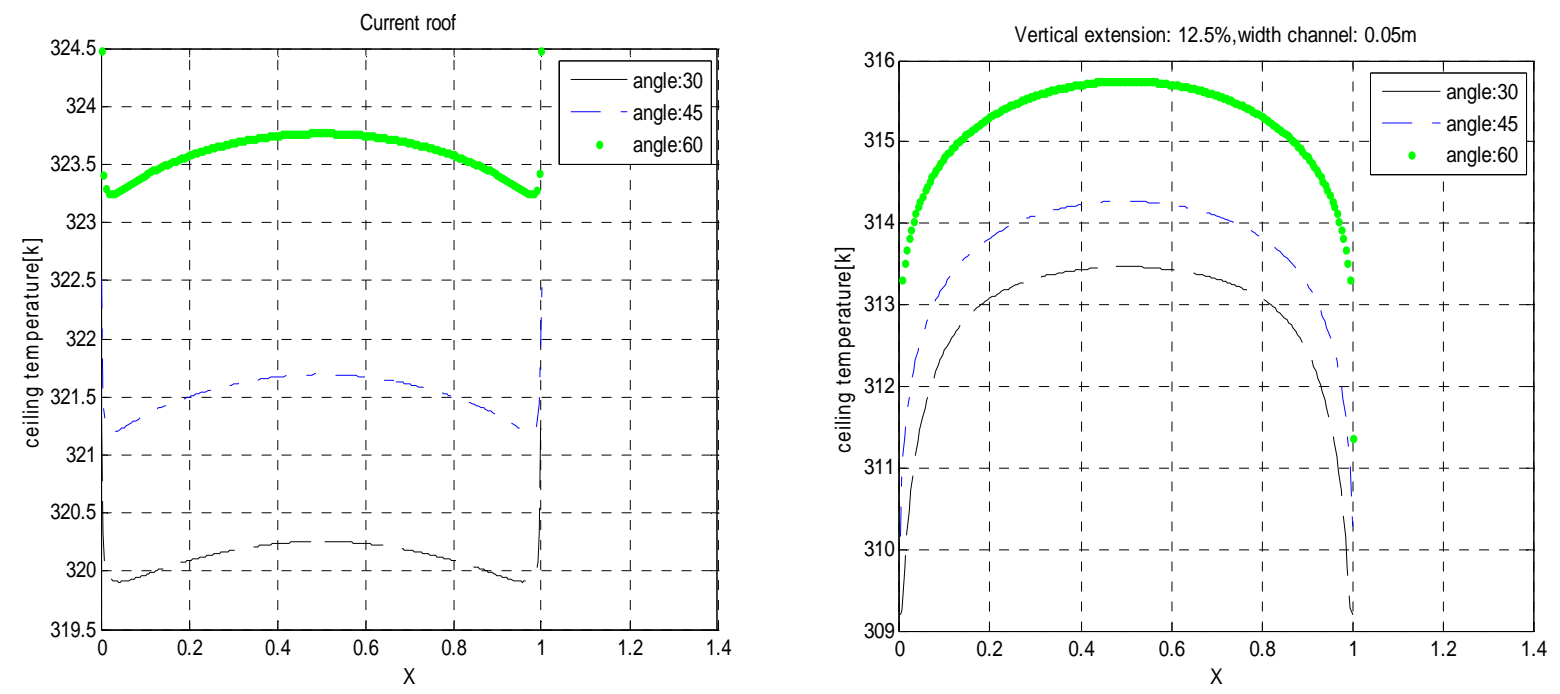

Figure 20. Temperature comparison in the ceiling at different tilt angles

At $30^{\circ}$ of inclination and $2 \mathrm{~m}$ length of roof, the temperature decreases from $320.12 \mathrm{~K}$ to $312.82 \mathrm{~K}$, this represents a reduction of $2.28 \%$. When higher angles are considered, this reduction is improved to $2.44 \%$ at $45^{\circ}$, and $2.59 \%$ at $60^{\circ}$.

In this figure, the ceiling length is determined by $\mathrm{X}$, which is the ratio of the particular length, corresponding to the position evaluated, to the total ceiling length. This variable was introduced in order to evaluate the curves of temperature overlapping at different lengths of the ceiling, and will be used in most of the graphs associated with this surface.

\subsubsection{Influence of the width of the channel}

The width of channel has played a major role in the analysis completed so far, influencing greatly the velocity and mass flow, and consequently in the rates of reduction 
of the temperatures. However, its powerful contribution is limited by the thermal boundary layer thickness. At values much bigger than this breadth, the natural ventilation effect could be considered only the obtained at the outer surface of the current roof model. Figure 21 shows the ceiling temperatures, when the channel width values vary from $0.05 \mathrm{~m}$ to $0.15 \mathrm{~m}$, and length of roof equal to $2 \mathrm{~m}$.

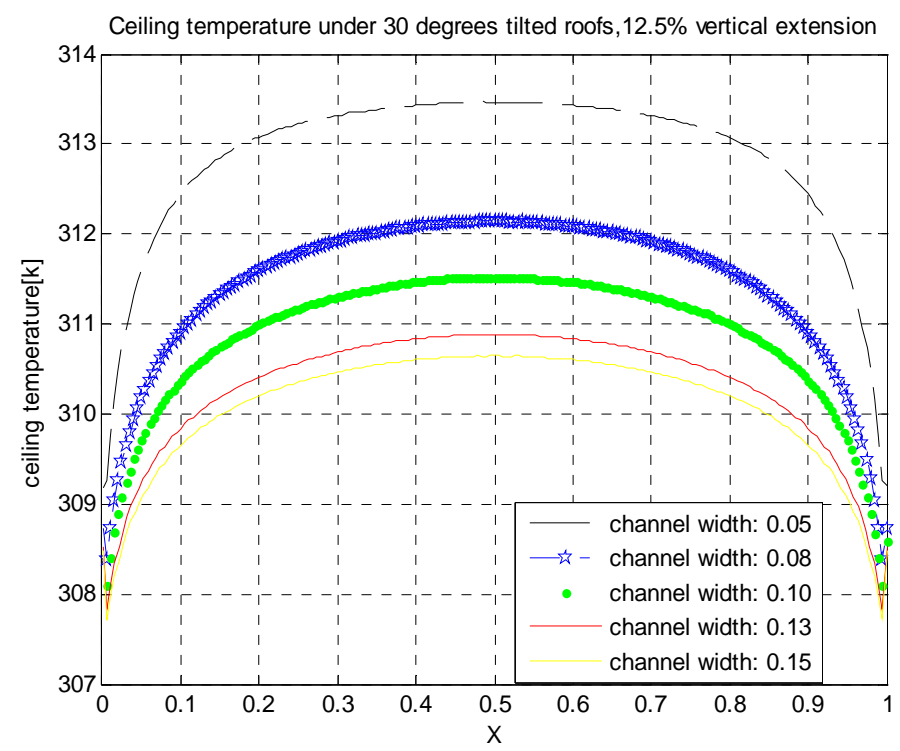

Figure 21. Temperature distribution in the ceiling, different channel widths [m]

The mean temperature reduction of the ceiling is considerable when the channel width is increased from $0.05 \mathrm{~m}$ to $0.08 \mathrm{~m}$; however, it begins to be less evident when it approaches $0.15 \mathrm{~m}$. The limitation, mentioned previously, is shown in Figure 22, after $0.15 \mathrm{~m}$, the mean temperature in the ceiling increases in $2 \mathrm{~K}$, after which it is kept constant through even larger distances between surfaces. When the thermal boundary layer of one surface does not influence the other, the upper roof approaches only the barrier effect over the lower roof. 


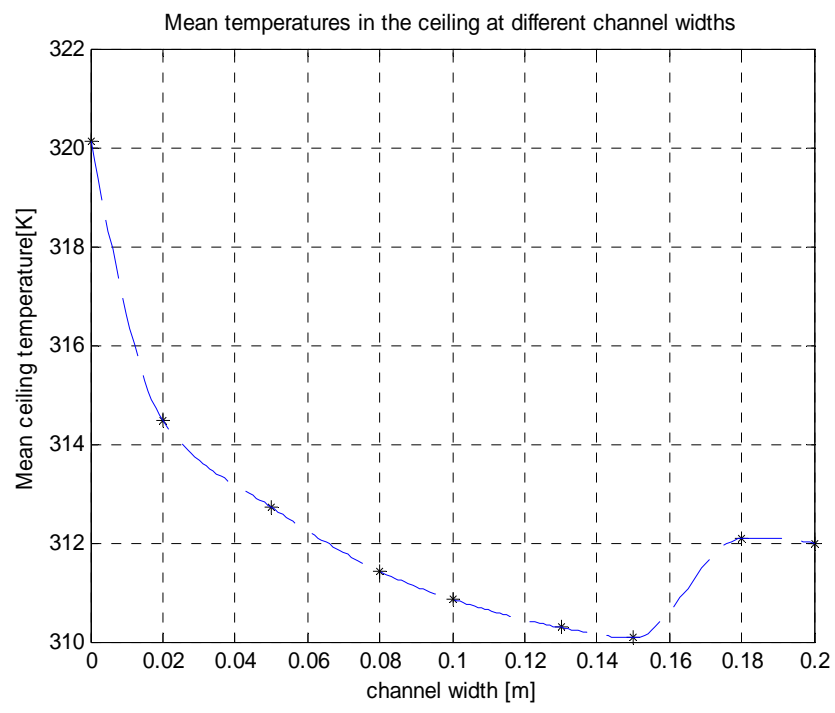

Figure 22. Mean temperature at the ceiling at different channel widths

The minimum mean temperature in this curve is $310 \mathrm{~K}$ and corresponds to $30^{\circ}$ of inclination, $12.5 \%$ of vertical extension and $0.15 \mathrm{~m}$ of channel width. It represents a reduction of $3.14 \%$ in the mean ceiling temperature.

\subsubsection{Influence of the vertical extensions}

The vertical extension is useful since it allows the channel to have part of it in the vertical position which is the more enhancing position for the buoyancy forces, as expressed by Equation 3.32.

The effect of having a vertical extension in the upper part of the roof gains in importance at higher tilt angles, but this effect is less noticeable than that observed by increasing the channel width. Figure 23 shows the ceiling temperatures corresponding to different vertical extensions at two tilt angles. 

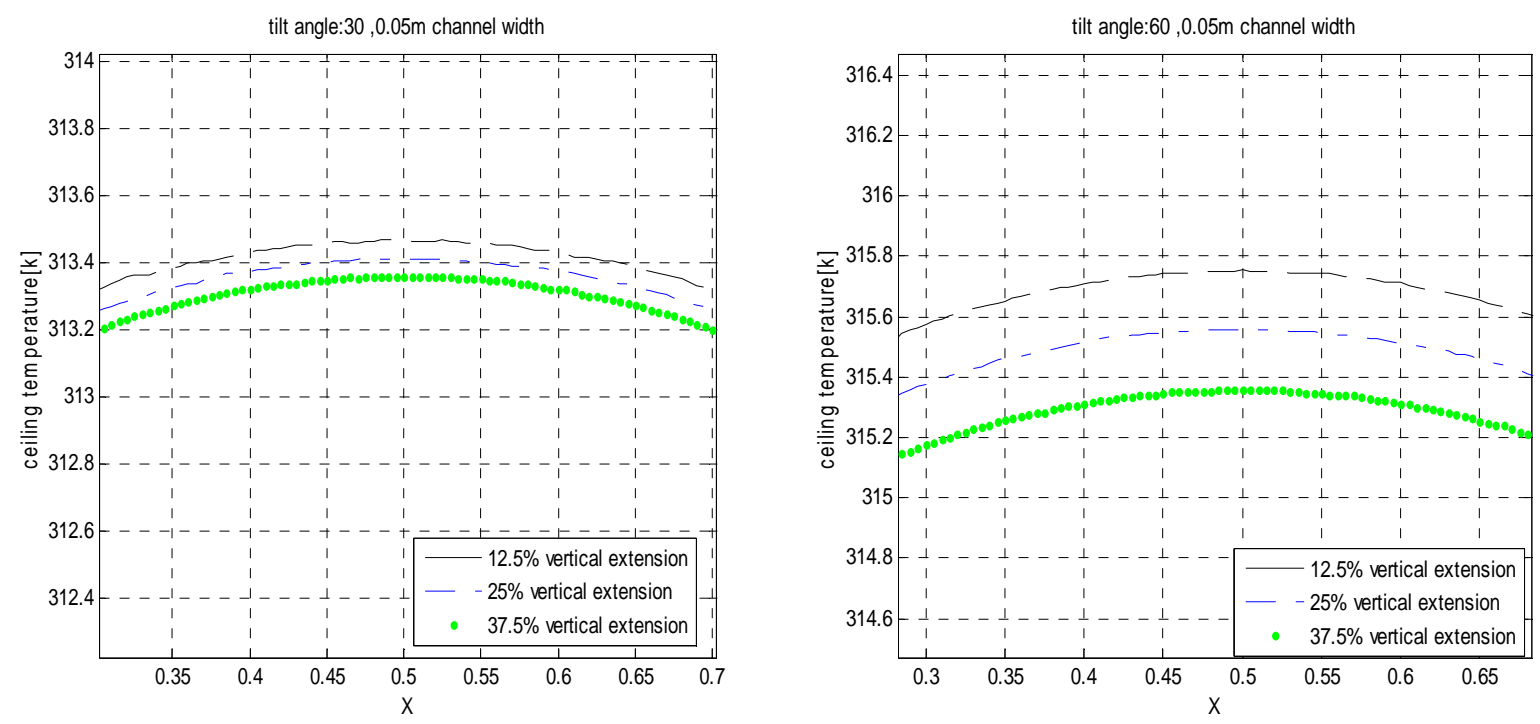

Figure 23. Ceiling temperature at different vertical extensions

Figure 24 shows an almost linear reduction of the temperature at various extensions, although this reduction is only about $1 \mathrm{~K}$ per meter of extension. The $\mathrm{L}$ value considered was $2 \mathrm{~m}$.

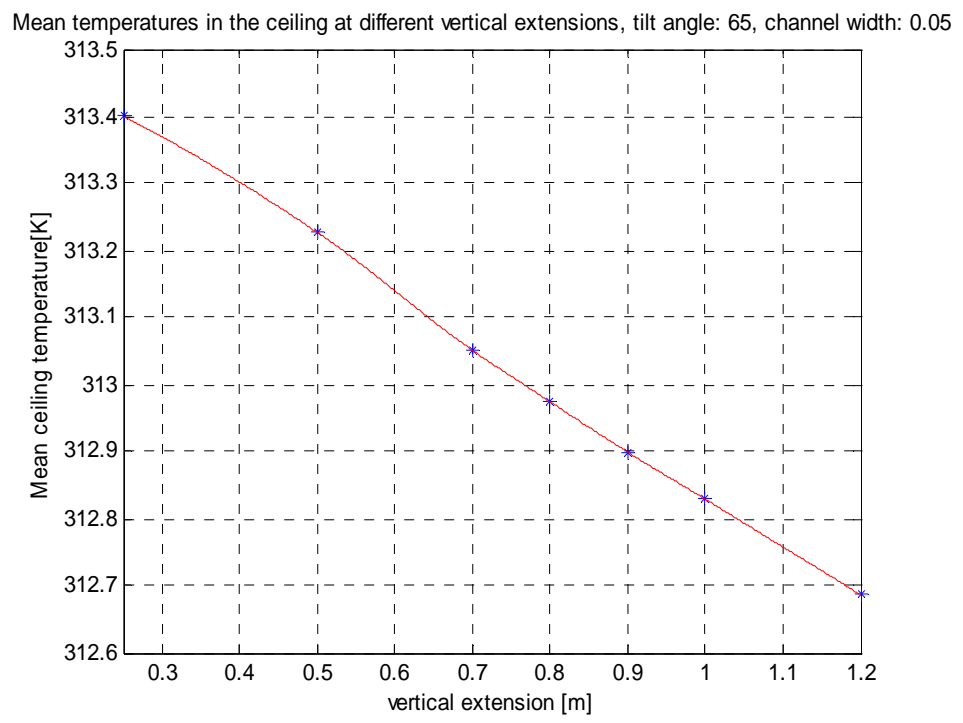

Figure 24. Variation of the mean temperatures of the ceiling, at different vertical extensions 
Figure 25 presents a direct comparison between the temperatures achieved after increasing the vertical extension and the channel width lengths. The roofs are characterized by $\mathrm{L}=6 \mathrm{~m}$ and $45^{\circ}$ of inclination.
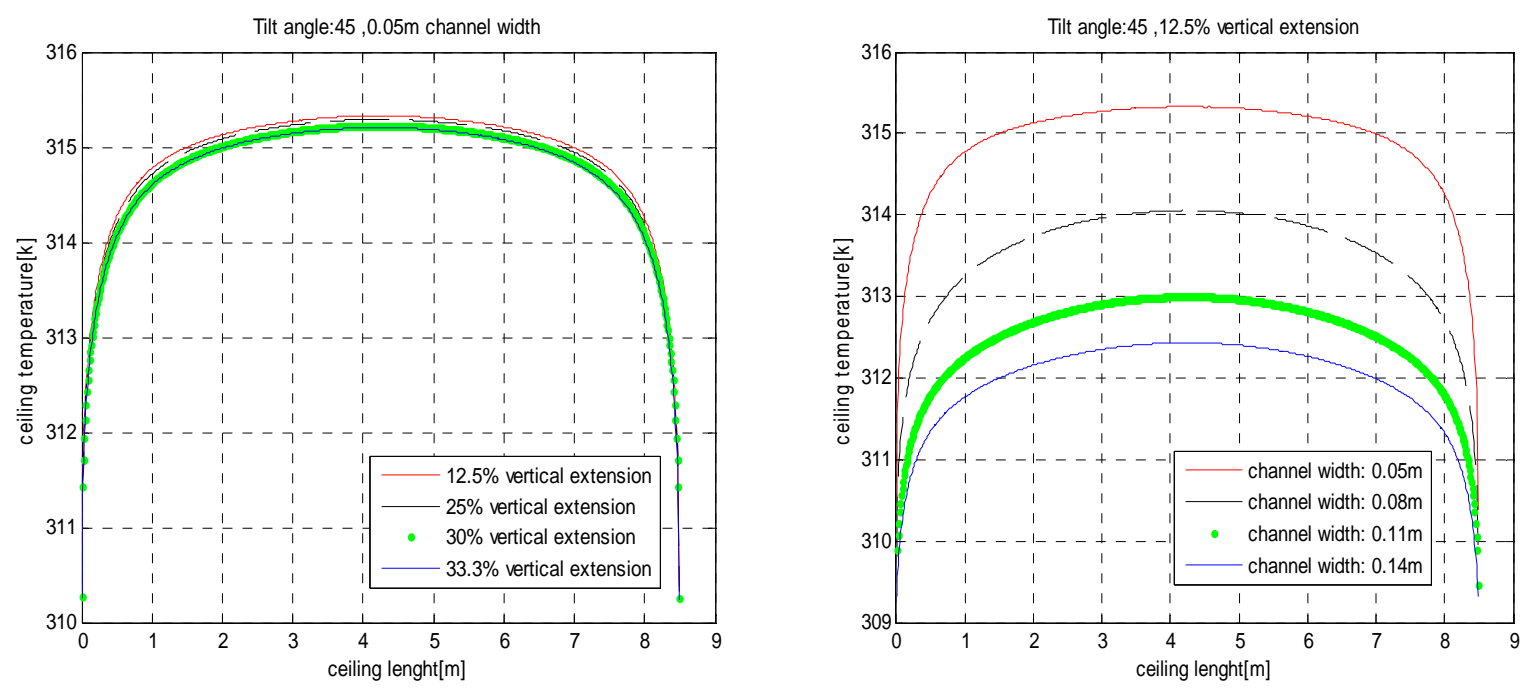

Figure 25. Comparison of ceiling temperatures at different vertical extension and channel width lengths

These graphs illustrate the conclusions arrived previously, while the mean temperature of the ceiling is slightly reduced by increasing the vertical extension, the increasing of the channel width within certain values enhances strongly this reduction.

\subsection{Heat flux through the ceiling}

The following curves summarize what the proposed roof can offer under the conditions studied. 

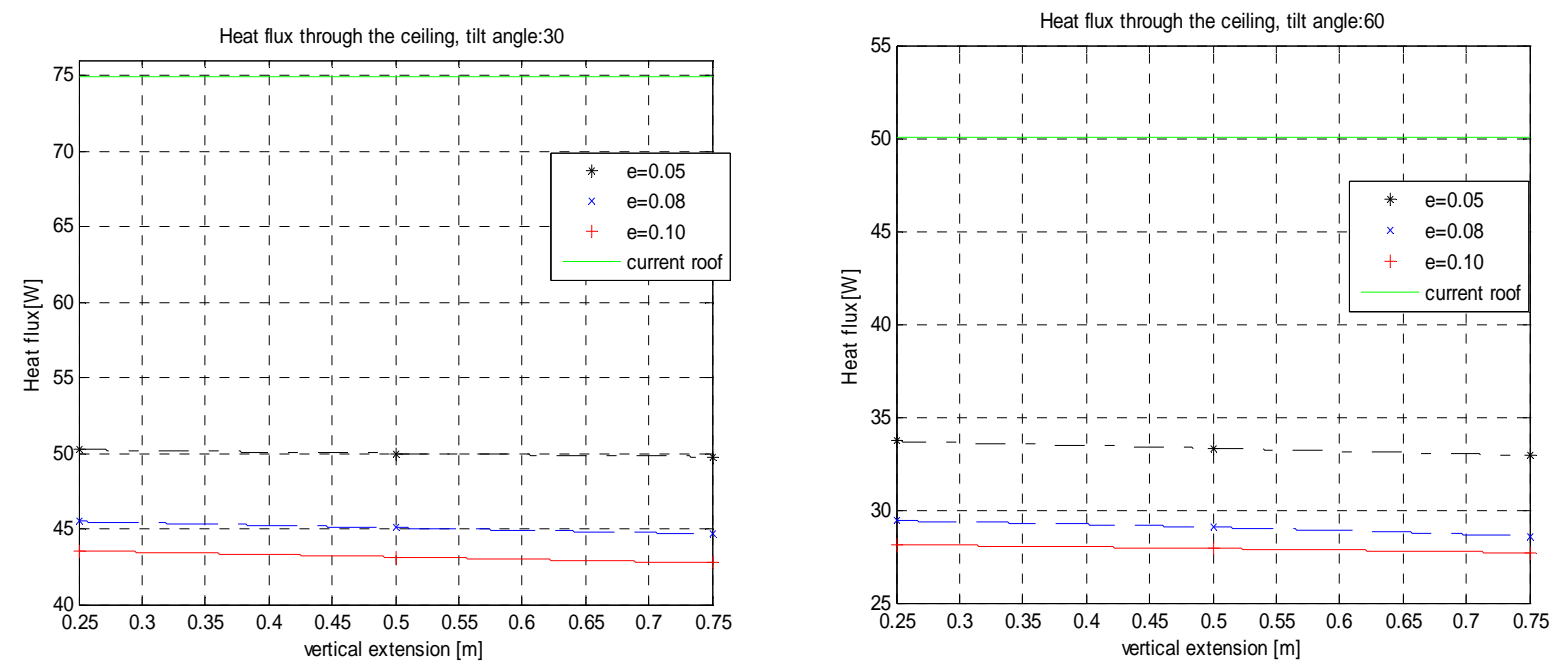

Figure 26. Heat flux through the ceiling at different dimensions

The influence of the variables analyzed reflects the previous results; higher tilt angles augment the reduction rates and enhances the vertical extension effect. Likewise, the influence of the channel width over the heat flux rates is considerable. Here it is important to mention that the larger roof area of the evaluated cases is obtained at $30^{\circ}$ of inclination, consequently the heat flux is larger in this case and contrasts with its higher R-value.

Another comparison between the effect of increasing the vertical extension and the channel width shows the magnitude of the reduction that these variables could achieve on the heat flux through the ceiling (Figure 27). The dimensions of the roofs considered in this case are $\mathrm{L}=6 \mathrm{~m}$ and $45^{\circ}$ tilt angle. 

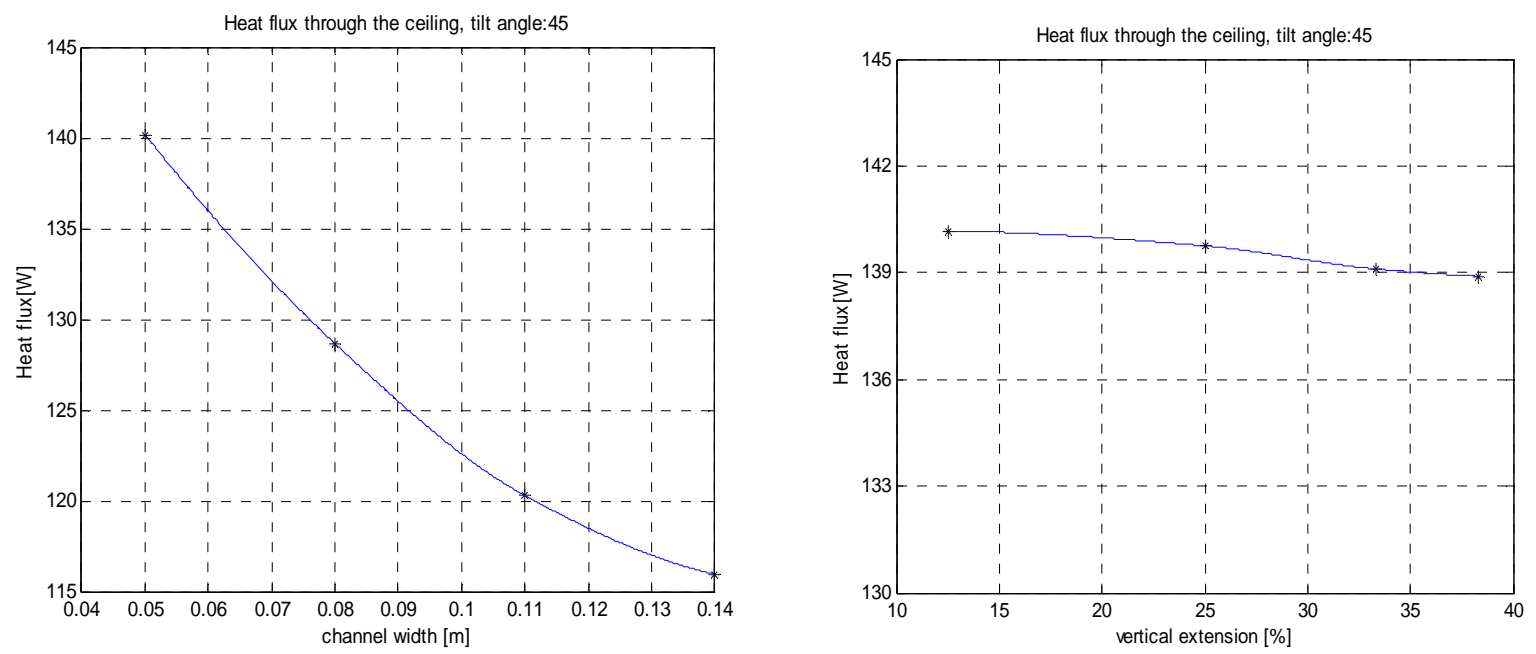

Figure 27. Comparison of ceiling heat fluxes at different vertical extension and

\section{channel width lengths}

Since the indoor temperature was considered the ideal for thermal comfort $\left(75^{\circ} \mathrm{F}\right)$, the heat flux entering the dwelling though the ceiling must be totally removed by the air conditioning system (among other heat loads), so that these figures are strongly related to the capacity of the system for potential consumption savings. 


\section{Chapter 5 Conclusions}

The effect of a natural ventilation system on a typical dwelling roof has been investigated under summer conditions. Different geometries for the roof design were considered in addition to the constant outdoor and indoor conditions. The materials used were those that currently are employed for most roofs. The particular effects of these components have not been evaluated.

Special emphasis was given to the changes observed in the ceiling temperature and the heat flux through this surface, since it constitutes the heat load entering into the interior of the building and which is necessary to be removed in order to keep the appropriate temperature for thermal comfort.

The governing equations of the problem were solved by using the software package Fluent. Several combinations of the dimension values were set up in order to realize their influence in the phenomena. Experimental data was used to validate the procedure used to face natural convection.

The increasing of the roof tilt angle improves the natural ventilation conditions according to the favorable orientation that it provides for the buoyancy forces. The vertical orientation constitutes the ideal position since it is aligned to the gravitational field action. The reduction of the mean temperature of the ceiling was conditioned by the radiation head load transferred, which parameters, such as emissivity and effective temperature are affected by the attic enclosure geometry. The reduction in the main 
temperature obtained by a channel width equal to $0.05 \mathrm{~m}$ and $12.5 \%$ of $\mathrm{L}$ in the vertical extension is $2.28 \%$ at 30 degrees, $2.45 \%$ at 45 degrees and $2.59 \%$ at 60 degrees. The reduction in the heat flux through the ceiling is $32.9 \%$ at 30 degrees, $33.3 \%$ at 45 degrees and $41.6 \%$ at 65 degrees.

The effect of the width of the channel is important since the channel area influences the mass flow strongly. This length is conditioned by the boundary layer thickness, and has been observed that for values larger than $0.15 \mathrm{~m}$, the natural ventilation effect becomes weak. Also, the ratio of temperature reduction is higher around $0.08 \mathrm{~m}$. Keeping the tilt angle and vertical extension constant, a reduction in the mean temperature of the ceiling can be increased from $2.28 \%$ at $0.05 \mathrm{~m}$ of width of channel to $3.14 \%$ at $0.15 \mathrm{~m}$. Similarly, the heat flux reduction grows from $32.9 \%$ to $45.4 \%$ under the same increases in channel widths.

The vertical extension on the upper roof allows the channel to have part of it in the desirable vertical position. The reduction obtained by increasing this extension has been observed to be linear, but at the same time much lower than that obtained by certain widths of channel. It is necessary to mention that the best rates of reduction in the ceiling heat flux obtained by increasing this length is seen at higher tilt angles. Considering a tilt angle value equal to 65 degrees and $0.05 \mathrm{~m}$ of channel width, the reduction in the heat flux into the living interior is $41.56 \%$ at $12.5 \%$ of vertical extension and $44.29 \%$ when this extension is $60 \%$ of the roof side length.

In summary, the key factors involved in the geometry of the proposed roof are the width of the channel and the tilt angle, respectively. The vertical extension becomes more 
helpful at higher tilt angles, but its benefit is less than that obtained by the mentioned dimensions. 


\section{Chapter $6 \quad$ Recommendations}

Recognizing the importance of radiation heat transfer in the attic-roof system, the analysis of parameters such as emissivity, factor of view, reflectivity, etc. can be done in the proposed roof and other natural convection systems.

In addition to the advantages shown in weight and durability by new materials, the thermal response when forming part of natural ventilation systems should be investigated. Not only in insulating materials used as barriers in the attic, but the material used for the internal and external surfaces.

The adaptability of natural convection models to winter conditions is also recommended. Since the air possesses low conductivity, there is the possibility of, under certain design conditions; that this could act as an insulating material.

A two dimensional analysis of the introduced system could provide a more realistic idea of the heat transfer behavior along the surfaces, since the temperature does not remain constant in space necessarily.

A transient analysis of the introduced system must be considered in future work, in order to know the achievable overall power savings in a day. 


\section{REFERENCES}

[1] Y. Çengel. Heat Transfer a Practical Approach. WCB/McGraw-Hill. International Edition. New Jersey, 1998.

[2] Energy Information Administration. Official Energy Statistics from the United States Government.

[3] S. Ostrach. "Natural Convection in Enclosures". Journal of Heat Transfer 110 (1988): 1175-1190.

[4] V. Dubovsky, et al. "Natural Convection inside Ventilated Enclosure heated by Downward-Facing Plate: Experiments and Numerical Solutions". International Journal of Heat and Mass Transfer 44 (2001): 3155-3168.

[5] T. Nishimura, et al. "Natural Convection Heat Transfer in Enclosures with Multiple Vertical Partitions”. International Journal of Heat and Mass Transfer 31 (1988): 1679-1686.

[6] D. Poulikakos and A. Bejan. "The Fluid Dynamics of an Attic Space”. Journal of Fluid Mechanics 131 (1982): 991-998.

[7] R. D. Flack, et al. "The Measurement of Natural Convective Heat Transfer in Triangular Enclosures". Journal of Heat Transfer 101 (1979): 648-654.

[8] R. Flack, et al. "Measurement and Prediction of Natural Convection Velocities in Triangular Enclosures". International Journal of Heat and Fluid Flow 16 (1995): 106-113. 
[9] C. Balaji and S. P. Venkateshan. "Correlations for Free Convection and Surface Radiation in a Square Cavity". International Journal of Heat and Fluid Flow 15 (1994): 249-251.

[10] M. Behnia, et al. "Combined Radiation and Natural Convection in a Rectangular Cavity with a Transparent Wall and containing a Non-participating Fluid". International Journal of Numerical Methods Fluids 10 (1990): 305-325.

[11] B. Lacarriere, et al. "Experimental Unsteady Characterization of Heat Transfer in a Multi-layer Wall including Air Layers-Application to Vertically Perforated Bricks". Energy and Building 38 (2006): 232-237.

[12] S. Ergin. "Surface Radiation with Conduction and Natural Convection in a Twofloor Enclosure". Energy and Buildings 32 (2000): 57-70.

[13] N. Bansal, et al. "Solar Chimney for Enhanced Stack Ventilation". Building and Environment 28 (1993): 373-377.

[14] Z. Chen, et al. "An Experimental Investigation of a Solar Chimney Model with Uniform Wall Heat Flux". Building and Environment 38 (2003): 893-906.

[15] M. Aboulnaga and S. Abdrabboh. "Improving Night Ventilation into Low-Rise Building in Hot-Arid Climates exploring a Combined Wall Solar Chimney". Renewable Energy 19 (2000): 47-54.

[16] J. Mathur, et al. "Summer-performance of Inclined Roof Solar Chimney for Natural Ventilation”. Energy and Building 38 (2006): 1156-1163.

[17] J.F. Mathews, III. "Construction utilizing a Passive Air System for the Heating and Cooling of a Building Structure". United States Patent No 4677903, 1987. 
[18] S. H. Lanyon. "Sectionally Supported Air Cooled Wall". United States Patent No $1969892,1932$.

[19] W. L. Pigg. "Ventilated Roof and Wall Structure". United States Patent No $5487247,1996$.

[20] W. Stoll and A. Thallemer. "Roof of a Structure". United States Patent No 5901504, 1996.

[21] H. Asan and L. Namli. "Laminar Natural Convection in a Pitched Roof of Triangular Cross-Section: Summer Day Boundary Conditions". Energy and Buildings 33 (2000): 69-73.

[22] H. Asan and L. Namli. "Laminar Natural Convection in a Pitched Roof of Triangular Cross-Section: Winter Day Boundary Conditions". Energy and Buildings 33 (2000): 753-757.

[23] S.C. Tzeng, et al. "Numerical Simulation-Aided Parametric Analysis of Natural Convection in a Roof of Triangular Enclosures". Heat Transfer Engineering 26(2005): 69-79.

[24] P.W. Messick. "Building Roof Structure". United States Patent No 4228729, 1980.

[25] T.B. Thong, et al. "Simulations of Flow in a Solar Roof Collector Driven by Natural Convection". Proceedings: $16^{\text {th }}$ Australasian Fluid Mechanics Conference. Australia 2007. 667-670.

[26] W. A. Miller, et al. "The Impact of Above-Sheathing Ventilation on the Thermal and Moisture Performance of Steep-Slope Residential Roofs and Attics". 
Proceedings: $15^{\text {th }}$ Symposium on Improving Building System in Hot and Humid Climates, Orlando FL, 2006.

[27] W. Miller, et al. "Natural Convection Heat Transfer in Roofs with AboveSheathing Ventilation". ASHRAE, 2007.

[28] G. V. Fracastoro, et al. "Reducing Cooling Loads with Under Roof Air Cavities". Proceedings: AIVC $18^{\text {th }}$ Conference. Greece, 1997. 477-486.

[29] A. Lacena-Neildez. "Modelling and Experimental Study of Heat Transfer in Innovative Building Components for Industrial Production". Ph.D. Thesis, Ecole Nationale Superieure des Mines de Paris, 2000.

[30] P. H. Biwole, et al. "Heat Transfer in a Double-Skin Roof Ventilated by Natural Convection in Summer Time". Energy and Building 40 (2008): 1487-1497.

[31] P. C. Chang, et al. "Development and Preliminary Evaluation of Double Roof Prototypes incorporating RBS (Radiant Barrier System)". Energy and Buildings 40 (2008): 140-147.

[32] L. F. Azevedo and E. M. Sparrow. "Natural Convection in Open-Ended Inclined Channels". Journal of Heat Transfer 107 (1985) 893-901.

[33] R. Letan, et al. "Ventilation by Natural Convection in a One-Story Building". Building and Environment 34 (2002): 91-102.

[34] R. Letan, et al. "Passive Ventilation and Heating by Natural Convection in a Multi-Story Building”. Building and Environment 38 (2003): 197-208.

[35] S. Ostrach. "Laminar Natural Convection Flow and Heat Transfer of Fluid with and without Heat Transfer in Channel with Constant Wall Temperature". NACA, Technical Note 2863, 1952. 
[36] O. Link. "Car-Roof". United States Patent No. 665642, 1901.

[37] C. Bird and P. Allen. "Means for Attaching Flexible Roofing Material to CarRoofs". United States Patent No 761138, 1904.

[38] F. Struben. "Roof Structure for Mobile Homes". United States Patent No 4570396, 1986.

[39] R. Orter. "Sun Shield Roof for House Trailers". United States Patent No 2602406, 1952.

[40] J. Smith et al. "Thermal Protection Apparatus and Method for ISO Containers". United States Patent Application, 2007.

[41] Hansen. "Thermodynamic Air Envelope for Food Storage Structure". WO 9119864, 1991.

[42] H. Wittrien. "Heat Protector Roof Construction for Vehicles". United States Patent 2629347, 1953.

[43] F. P. Incropera and D. De Witt. Fundamentals of Heat and Mass Transfers. 4th ed., Wiley \& Sons, New York, 1996.

[44] H. Schlichting. Boundary Layer Theory. McGraw-Hill Book Company Inc, 8th Edition, 1999.

[45] W. Aung, et al.. "Developing Laminar Free Convection between Vertical Flat Plates with Asymmetric Heating". International Journal of Heat and Mass Transfer, 15 (1972): 2293-2308.

[46] American Society of Heating, Refrigeration, and Air-Conditioning Engineers (ASHRAE). Handbook of Fundamentals. Atlanta, 1993.

[47] FLUENT User's Guide, Version 4.52, Fluent Incorporated. 